\title{
Wind Load Reduction in Hollow Panel Arrayed Set
}

\author{
Michalina Markousi, Dimitrios K. Fytanidis, and Johannes V. Soulis \\ Fluid Mechanics/Hydraulics Division, Department of Civil Engineering, Democritus University of Thrace, 67100 Xanthi, Greece \\ Correspondence should be addressed to Michalina Markousi; mmarkous@civil.duth.gr
}

Received 12 February 2016; Accepted 6 June 2016

Academic Editor: Valerio Lo Brano

Copyright (C) 2016 Michalina Markousi et al. This is an open access article distributed under the Creative Commons Attribution License, which permits unrestricted use, distribution, and reproduction in any medium, provided the original work is properly cited.

\begin{abstract}
Reducing the wind loading of photovoltaic structures is crucial for their structural stability. In this study, two solar panel arrayed sets were numerically tested for load reduction purposes. All panel surface areas of the arrayed set are exposed to the wind similarly. The first set was comprised of conventional panels. The second one was fitted with square holes located right at the gravity center of each panel. Wind flow analysis on standalone arrayed set of panels at fixed inclination was carried out to calculate the wind loads at various flow velocities and directions. The panels which included holes reduced the velocity in the downwind flow region and extended the low velocity flow region when compared to the nonhole panels. The loading reduction, in the arrayed set of panels with holes ranged from $0.8 \%$ to $12.53 \%$. The maximum load reduction occurred at $6.0 \mathrm{~m} / \mathrm{s}$ upwind velocity and $120.0^{\circ}$ approach angle. At 30.00 approach angle, wind load increased but marginally. Current research work findings suggest that the panel holes greatly affect the flow pattern and subsequently the wind load reduction. The computational analysis indicates that it is possible to considerably reduce the wind loading using panels with holes.
\end{abstract}

\section{Introduction}

Renewable energy resources trends show an increase in solar energy usage. Existing photovoltaic installation system methods may differ in their design but all are strongly influenced by wind loads. Extreme winds can cause damage and reduce the photovoltaic systems effectiveness. High wind loads effects can possibly create the need for costly maintenance or even panel replacement. Given the growing demand for solar energy, the studies that have been conducted in the field of photovoltaic systems aerodynamic load reduction analysis are relatively few.

Chevalien and Norton [1] conducted a study which addresses the wind load problem for roof-mounted solar collector panels and their support structures. Kopp et al. [2] have carried out experimental studies on the torque evaluation created due to wind on photovoltaic arrays arranged in series. The peak system torque was generally observed to occur at approach azimuthal angles near the diagonals of the panel at $45.0^{\circ}, 135.0^{\circ}, 225.0^{\circ}$, and $315.0^{\circ}$ although large loads also occurred at $270.0^{\circ}$, where wind is in the plane of the panel perpendicular to the individual modules. Chung et al. [3] conducted experimental study of a scaled commercial system to investigate the mean surface pressure distributions and uplift forces at different wind speeds resulting in the following: the wind uplift is effectively reduced with a guide plate placed normal to wind direction. Chou et al. [4] investigated experimentally the effect of a crosswind on the aerodynamic characteristics of two different solar water heaters setups. The first one is a typical residential solar water heater and the second one is an inclined flat plate without the horizontal cylinder. The results revealed that at the near upwind corner the higher suction and fluctuating pressure are observed and that the presence of the horizontal cylinder increases the lift force.

Recent developments in computer technology and computing engineering make the application of Computational Fluid Dynamics (CFD) in wind engineering quite encouraging. Shademan and Hangan [5] carried out simulations to estimate the wind loads for various wind directions on standalone and arrayed panels. The study identified areas facing the greatest impact from wind loads and also observed that at a specific distance between two sets of panels the drag coefficient for the downstream sets of panels reaches a minimum. One year later, Shademan and Hangan [6] investigated wind loads on an array of panels for various wind directions using 


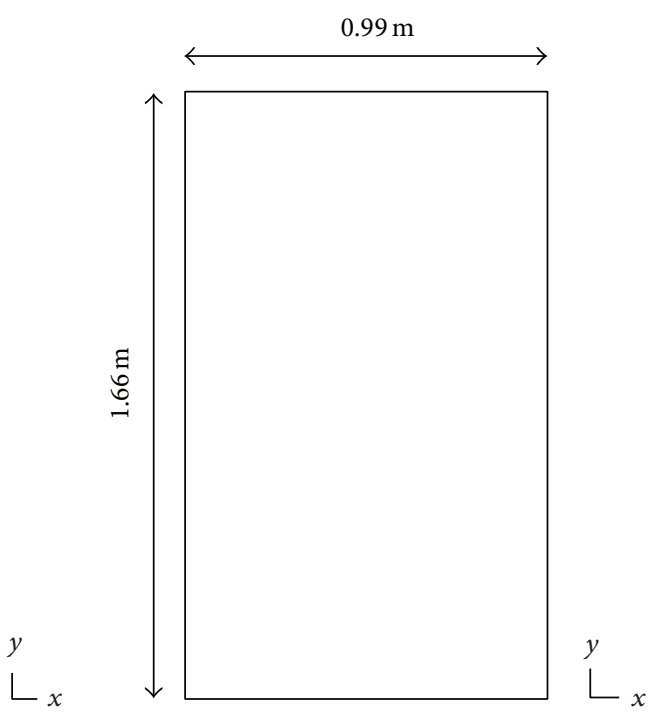

(a)

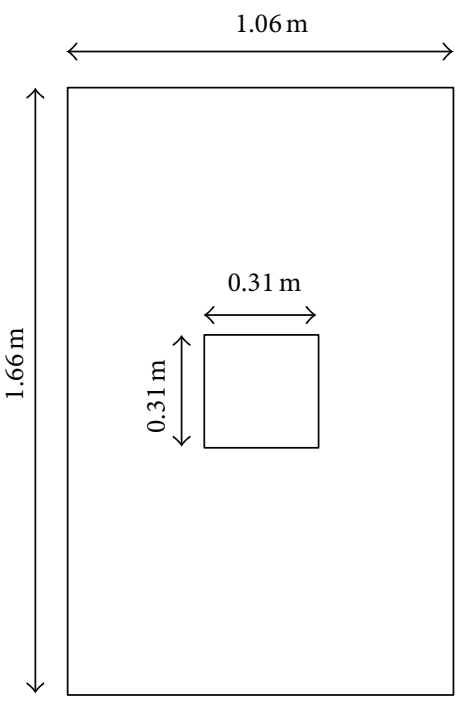

(b)

FIGURE 1: (a) Typical solar panel $0.99 \times 1.66 \mathrm{~m} \times \mathrm{m}$ and (b) a $0.31 \times 0.31 \mathrm{~m} \times \mathrm{m}$ rectangular shape hole cut at the panel gravity center. The solar panel with hole measures $1.06 \times 1.66 \mathrm{~m} \times \mathrm{m}$. Each panel type exposes to wind the same surface area.

CFD. The simulations identified the corner panels as the critical ones while more critical angles of wind incidence are $0.0^{\circ}$ and $180.0^{\circ}$. Bitsuamlak et al. [7] conducting a similar study attempted to investigate the aerodynamic features of groundmounted panels under atmospheric boundary layer flows using numerical techniques. The Reynolds Averaged Navier Stokes (RANS) equations turbulence modeling approach was adapted to obtain initial flow conditions for use by the more reliable Large Eddy Simulation (LES) technique. The calculated results have been compared and validated with full-scale experimental measurements concluding that LES underestimated the mean pressures compared to fullscale measurements. Meroney and Neff [8] used numerical analysis to calculate the wind loads on solar photovoltaic collector in order to estimate drag, lift, and overturning moments on different collector support systems. Results were compared with experimental measurements performed in wind tunnel. The comparison showed that the turbulence models that better approach the experimental measurements are the RNG $\mathrm{k}-\varepsilon$ and $\mathrm{k}-\omega$, whereas the $\mathrm{k}-\varepsilon$ model failed to replicate measurements. Jubayer and Hangan [9] used the shear stress transport (SST) k- $\omega$ turbulence closure for unsteady $3 \mathrm{D}$ numerical simulations in order to investigate the wind load and flow field around a ground-mounted standalone photovoltaic (PV) system. Simulation results compared with the wind tunnel measurements and an agreement within $46 \%$ is found.

In this study $3 \mathrm{D}$ numerical simulations were performed to investigate the wind load reduction on photovoltaic structures. Two arrayed sets of panels are considered to reduce the aerodynamic load: a standard photovoltaic structure (conventional) and a similar structure but with square holes evenly distributed exposing to the wind the same panel surface area. For each arrayed set of panels, a parametric analysis is performed relatively to approach angle and wind
TABLe 1: Panel dimensions and weight.

\begin{tabular}{lc}
\hline Length $(\mathrm{mm})$ & $1662.0( \pm 2.5)$ \\
Width $(\mathrm{mm})$ & $990.0( \pm 2.5)$ \\
Thickness $(\mathrm{mm})$ & 46.0 \\
Weight $(\mathrm{kg})$ & 21.0 \\
\hline
\end{tabular}

intensity. Purpose was to investigate the quantitative wind load reduction under the panels with holes presence.

\section{Methodology}

2.1. Geometry and Computational Grid. The conventional panel dimensions are $1662.0 \mathrm{~mm}$ long, $990.0 \mathrm{~mm}$ wide, and $46.0 \mathrm{~mm}$ thick, Table 1. Figure 1 shows the two geometries of the solar panel types used for computational analysis. A rectangular shape hollow, measuring $0.31 \times 0.31 \mathrm{~m} \times \mathrm{m}$, is cut at the panel gravity center for the panel shown in Figure 1(b). The actually tested geometry is comprised of an arrayed set of 12 panels arranged in 3 rows, Figure 2. Each row encompasses 4 panels and the gap between panels measures $0.02 \mathrm{~m}$. Each arrayed set of panels exposes to the wind the same panel surface area. This was on purpose done for wind loading comparison reasons and to ensure that the effective area, that is, the solar energy production, for both solar panels is equal.

The arrayed set of panels is placed at inclination angle $\beta$ of $26.0^{\circ}$ in relation to the flat ground surface, Figure 3(a). Longest panel axis is set parallel to north-south direction. However, a small gap $0.3 \mathrm{~m}$ was on purpose left between the lower panel end and the ground surface, Figure 3(a). This configuration closely approximates the reality. A schematic diagram showing the approach azimuthal angle is shown in Figure 3(b). 


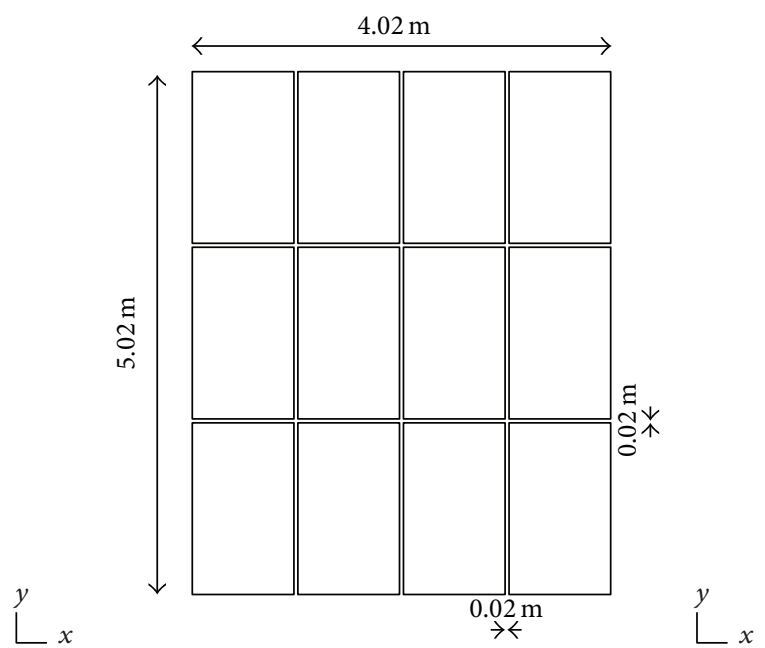

(a)

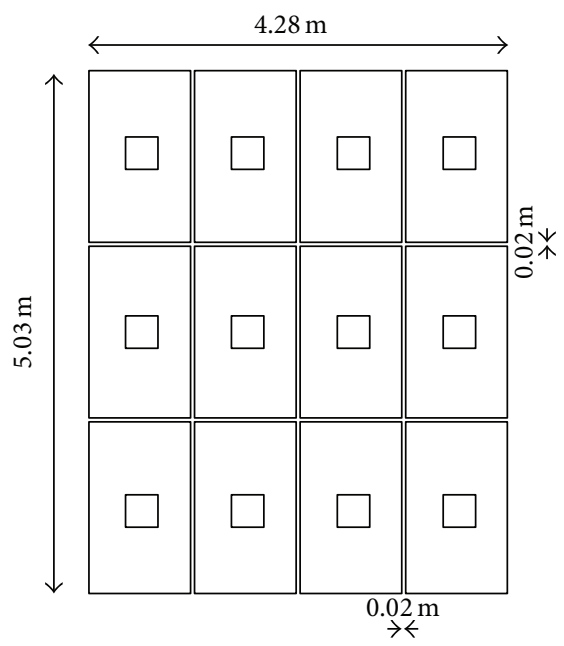

(b)

Figure 2: (a) Arrayed set of conventional solar panels $4.02 \times 5.02 \mathrm{~m} \times \mathrm{m}$ with gaps and (b) arrayed set of holes with solar panels $4.28 \times 5.03 \mathrm{~m}$ $\times \mathrm{m}$ with gaps. Panel types expose to the wind the same surface area.

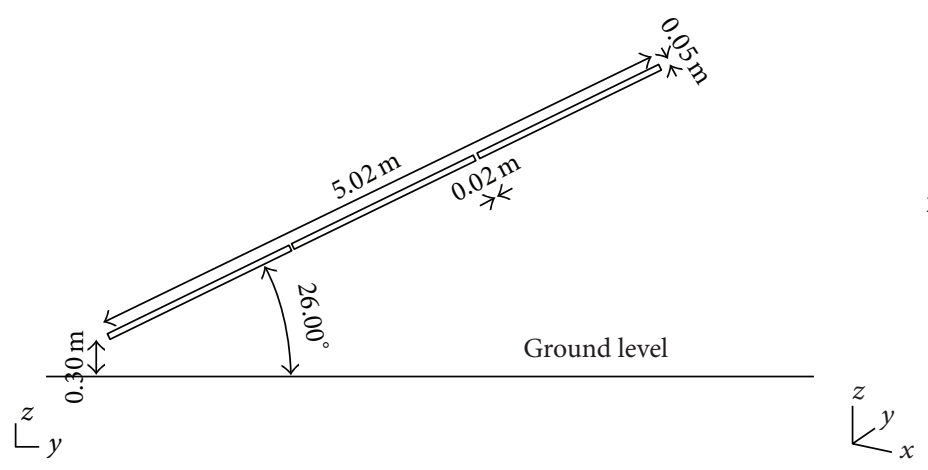

(a)

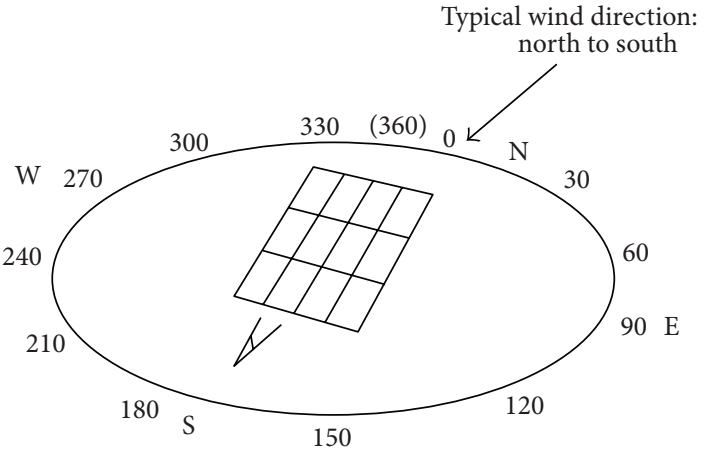

(b)

FIGURE 3: (a) Solar panels side view inclined at angle $\beta=26.0^{\circ}$ and (b) schematic diagram of the arrayed solar panels set. Longest panel axis is set parallel to north-south direction. The north is $0.0^{\circ}$. Azimuthal angles in degrees.

Figure 4 shows the utilized area for computational analysis. The geometry was constructed using the ANSYS-Design Modeler software and the grid generation was formed with the ANSYS-Meshing software package. The computational area is widely extended in all three dimensions to leave enough space for flow to be developed. A typical computational grid is shown in Figure 5. Grid nodes are densely located near to the panel flow regions. Some grid details in regions between panels (gaps) are shown in Figure 6. For a typical computational analysis, 1037091 grid nodes and 3524682 cells were used; see also Section 3.1. The number of the nonuniformly distributed grid nodes was considered to be satisfactory for subsequent analysis. The decision was made after numerical experimentation.

2.2. Governing Wind Flow Equations, Boundary Conditions, and Assumptions. The utilized numerical code utilizes the ANSYS-Fluent 14.0 solver. The wind flow is assumed to be 3D, steady, homogeneous, and incompressible with no external forces applied to it. To simulate the turbulence modeling the steady state RANS equations are solved. In their generality these equations are written as

$$
\begin{aligned}
\frac{\partial}{\partial x_{i}}\left(\rho u_{i}\right) & =S_{m} \quad \text { Continuity } \\
\frac{\partial}{\partial x_{j}}\left(\rho u_{i} u_{j}\right) & =-\frac{\partial p}{\partial x_{i}}+\frac{\partial \tau_{i j}}{\partial x_{j}}+\rho g_{i}+F_{i} \quad \text { Momenta }
\end{aligned}
$$

with

$$
\tau_{i j}=\left[\mu\left(\frac{\partial u_{i}}{\partial x_{i}}+\frac{\partial u_{i}}{\partial x_{i}}\right)\right]-\frac{2}{3} \mu \frac{\partial u_{i}}{\partial x_{i}} \delta_{i j} \quad \text { Shear stress. }
$$

$x_{i}$ represent the Cartesian coordinate positions in the longitudinal, transverse, and vertical directions, respectively; $\rho$ is the wind (air) density; $S_{m}$ are sources terms (zero in our case); 


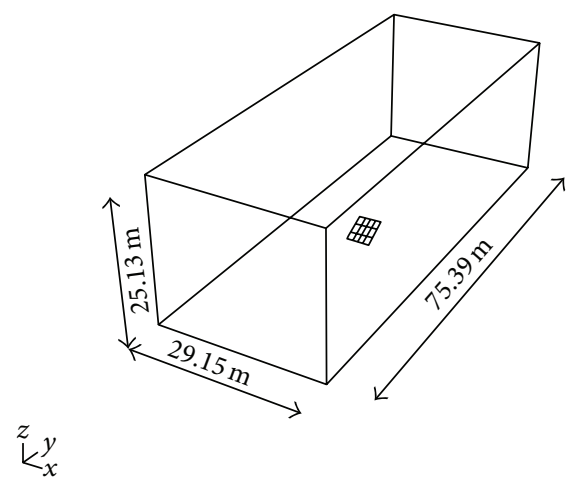

FIGURE 4: Arrayed set of solar panels and computational space used for analysis. The space geometry reads $75.39 \mathrm{~m}$ in length, $29.15 \mathrm{~m}$ in width, and $25.13 \mathrm{~m}$ in height.

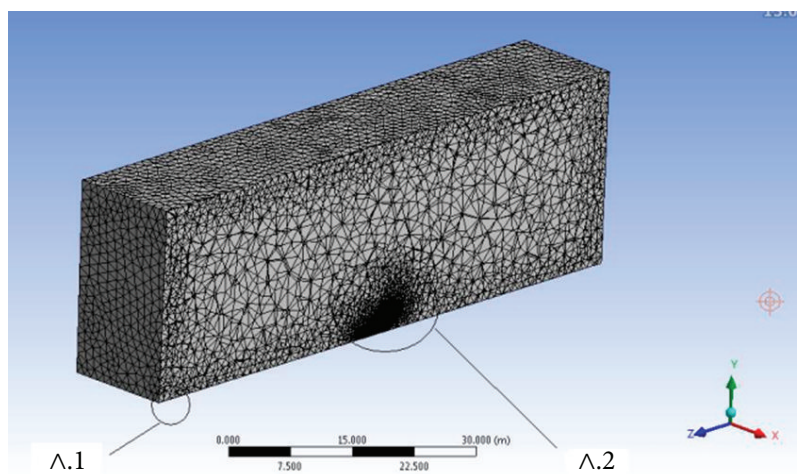

FIGURE 5: The computational grid is comprised of 1037091 grid nodes. Nodes are densely located close to solar panels.

$u_{i}$ are the velocity components in $x_{i}$ directions; $p$ is the static pressure; $g_{i}$ is the gravity acceleration along the $i$-axis; $F_{i}$ are the applied external forces; $\mu$ is the molecular viscosity; $\delta_{i j}$ is the Kronecker symbol; and $\tau_{i j}$ are the Reynolds stresses.

For panel wall surfaces as well as ground surfaces the no-slip boundary condition was adopted; that is, velocity components at the wall face must be zero. The symmetry conditions are applied for all free-side walls (surfaces) as this boundary condition is widely applied, Stangroom [10]. For the downstream surface a "pressure outlet" boundary condition is adopted, which corresponds to Dirichlet boundary condition and Neumann boundary condition for the velocities field. Table 2 shows the inflow boundary conditions used for computational analysis.

Examined independent variables are the wind velocity and the approach azimuthal angle. Wind velocity ranges from $6.0 \mathrm{~m} / \mathrm{s}$ to $14.0 \mathrm{~m} / \mathrm{s}$ with $2.0 \mathrm{~m} / \mathrm{s}$ step. The approach angles range from $360.0^{\circ}$ (or $0.0^{\circ}$, north) to $180.0^{\circ}$ with $30.0^{\circ}$ step, excluding the $90.0^{\circ}$ approach angle. The above range flow conditions cover typical applications regarding the north Hellenic State latitudes. The air density and molecular viscosity are set $1.225 \mathrm{~kg} / \mathrm{m}^{3}$ and $1.7894 \times 10^{-5} \mathrm{~kg} / \mathrm{m}$-s, respectively. The air turbulence intensity is set $16.0 \%$ at the inlet flow plane, Bitsuamlak et al. [7], and the turbulent length scale is calculated as $3.5182(=0.7 \times$ panels characteristic length

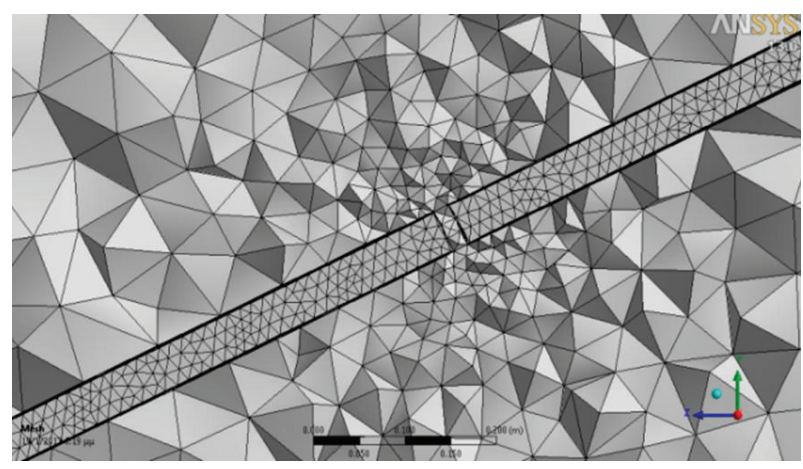

FIGURE 6: Computational grid gap details between solar panels.

TABLE 2: Approach azimuthal angles and velocity range for computational analysis.

\begin{tabular}{llllll}
\hline Angle (degrees) & \multicolumn{5}{c}{ Upwind velocity (m/s) } \\
\hline 0.0 & 6.0 & 8.0 & 10.0 & 12.0 & 14.0 \\
30.0 & 6.0 & 8.0 & 10.0 & 12.0 & 14.0 \\
60.0 & 6.0 & 8.0 & 10.0 & 12.0 & 14.0 \\
120.0 & 6.0 & 8.0 & 10.0 & 12.0 & 14.0 \\
150.0 & 6.0 & 8.0 & 10.0 & 12.0 & 14.0 \\
180.0 & 6.0 & 8.0 & 10.0 & 12.0 & 14.0 \\
\hline
\end{tabular}

TABLE 3: Number of cells in million for the used meshes.

\begin{tabular}{cccc}
\hline Cells & Coarse & Medium & Fine \\
\hline & $2.4 \times 10^{6}$ & $3.5 \times 10^{6}$ & $4.0 \times 10^{6}$ \\
\hline
\end{tabular}

of $5.03 \mathrm{~m}$ ). For ground surface, the roughness height is set $0.03 \mathrm{~m}$ with roughness constant 0.5 . For panels, the roughness height is set to $0.0000015 \mathrm{~m}$ with 0.5 roughness constant, Blocken et al. [11].

The aforementioned set of partial differential equations was solved using the numerical algorithms included in the commercial solver ANSYS-Fluent. For the spatial discretization, a first-order accuracy numerical scheme was utilized for all equations. The Semi-Implicit Method for PressureLinked Equations (SIMPLE) algorithm was applied for the velocity pressure coupling, Patankar [12], while the "RNG k$\varepsilon$ " turbulence model was used for the turbulence closure, with "standard wall functions" for the wall boundary treatment.

\section{Results}

3.1. Mesh Convergence Study. To investigate any differences in the simulation data resulting from mesh resolution, three unstructured Delaney tetrahedral grids were generated in ANSYS-Meshing. The number of cells used is shown in Table 3.

The mesh convergence analysis was performed at $30.0^{\circ}$ approach angle and $14.0 \mathrm{~m} / \mathrm{s}$ upwind velocity. The selected vertical profile location for mean velocities plotting is shown in Figure 7. Streamwise and lateral velocities profiles show good agreement with coarse, medium, and fine meshes, shown in Figure 8, with reference velocity $U_{\text {ref }}$ equal to 


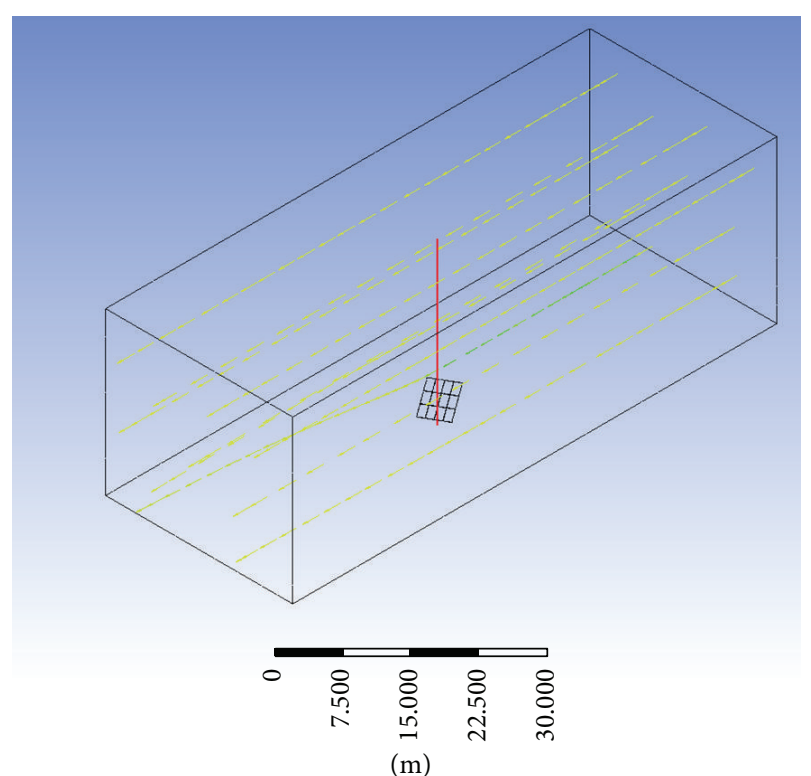

Figure 7: Profile location of the velocities plot for mesh convergence.

$14.0 \mathrm{~m} / \mathrm{s}$. No significant differences were observed for the velocity profiles using the three meshes.

\subsection{Static Pressure at the Upwind and Downwind Panel Sides.} A schematic diagram over the inclined solar panel is shown in Figure 9. High and low pressure fields are developing upand downwind of the panel flow regions, respectively.

Only a very limited amount of information results is given here. Contour graphics were performed using the CFDPOST software package. All currently reported research work results refer to $0.0^{\circ}$ approach angle and $14.0 \mathrm{~m} / \mathrm{s}$ (maximum available) upwind velocity unless otherwise noted. At this angle the arrayed longest panel axis is parallel to the northsouth direction, Figure 3(a). The wind velocity magnitude is considered as a moderate one but realistic for analysis. Ogedengbe [13] in his analysis reports maximum wind velocities up to $23.0 \mathrm{~m} / \mathrm{s}$. At the same time, the approach angle was set $0.0^{\circ}$ because this is the dominant wind direction in north Hellenic State latitudes.

Static pressure $\left(\mathrm{N} / \mathrm{m}^{2}\right)$ contours for the up- and downwind conventional panel sides are shown in Figure 10. The upwind surface exhibits high wind pressure. The lower downwind panel surface part exhibits higher pressure than the upper one due to the escape corridor developing underneath. The downwind panel surface is less loaded. Panel gaps alter the pressure field mostly at the downwind panel region. Near symmetry of pressure flow distribution is preserved in either panel side. Static pressure contours at panels with holes for the up- and downwind panel sides are shown in Figure 11. Rectangular panel holes alter the static pressure flow field in the nearby regions. The near symmetry of the flow field is again preserved. At each hole, the upper side exhibits higher static pressure than the lower one. The overall static pressure pattern is altered in either panel side in comparison to the nonholes panel. The pressure differences across the panels with holes are now reduced. Again, the lower upwinding surfaces for either panel formation are highly loaded due to escape corridor between panels and ground surface.

3.3. Side View of Velocity and Static Pressure. To elucidate the flow velocity pattern, it was decided to present the results in two arrayed set panel cross sections, shown schematically in Figure 12. Section 1 plane is located in meridional direction (north to south). It divides the arrayed set of panels into two regions leaving two panel series on the left- and two on the right-hand side. Its actual location is adjacent to the central panel gap. Section 2 is a plane perpendicular to Section 1 (mid arrayed panel height). It divides the arrayed set of panels into two parts, namely, the upper half and the lower one.

Velocity magnitude $(\mathrm{m} / \mathrm{s})$ and static pressure $\left(\mathrm{N} / \mathrm{m}^{2}\right)$ contours at conventional panels over Section 1 are shown in Figures 13(a) and 13(b), respectively. Top velocity magnitude reaches $20.0 \mathrm{~m} / \mathrm{s}$ just above the panels tip at the downstream panel side. A wide rirculation area develops at the downstream flow region. Part of the wind escapes between the lower tip panel and ground surface, Figure 13(a). High pressure difference develops between up- and downwind panel surface and pushes it, Figure 13(b).

Corresponding velocity magnitude $(\mathrm{m} / \mathrm{s})$ and static pressure $\left(\mathrm{N} / \mathrm{m}^{2}\right)$ contours at panels with holes are shown in Figures 14(a) and 14(b), respectively. Both velocity and pressure field patterns are drastically altered in comparison to the nonhole panels. In this case the maximum velocity magnitude falls to $17.56 \mathrm{~m} / \mathrm{s}$. No distinct recirculation region is present unlike panels with nonhole holes, Figure 13(a). The pressure differences between panel sides have now been reduced. Highest pressure differences occur at the panels tip. The pressure field at the downwind side is relatively uniform compared to the nonhole panel.

Velocity magnitude $(\mathrm{m} / \mathrm{s})$ and static pressure $\left(\mathrm{N} / \mathrm{m}^{2}\right)$ contours for conventional panels at Section 2 (Figure 12) are shown in Figures 15(a) and 15(b), respectively. The flow field is symmetrical and the maximum velocity magnitude occurs at the far downwind flow region. Small strength vortices develop at the left and right panel tips. Gaps between panels disrupt the flow velocity field. High static pressures are uniformly present at the upwind surface. Low static pressure values are to be found in the near to downwind flow region, thus giving rise for pressure differences across the panel $240.0 \mathrm{~N} / \mathrm{m}^{2}$, Figure 15(b).

Corresponding velocity magnitude $(\mathrm{m} / \mathrm{s})$ and static pressure $\left(\mathrm{N} / \mathrm{m}^{2}\right)$ contours at Section 2 (Figure 12) for panels with holes are shown in Figures 16(a) and 16(b), respectively. It is again evident that the pressure differences between upand downwind surfaces now stand at $\sim 135.0 \mathrm{~N} / \mathrm{m}^{2}$ and are drastically altered (reduced) compared to the nonhole panels.

3.4. Side View Streamlines. Velocity magnitude (m/s) streamlined contours at conventional panels and panels with holes are shown in Figures 17(a) and 17(b), respectively. A large vortex has been developed at the downwind side, Figure 17(a). The vortex covers most of the adjacent downwind panel flow 


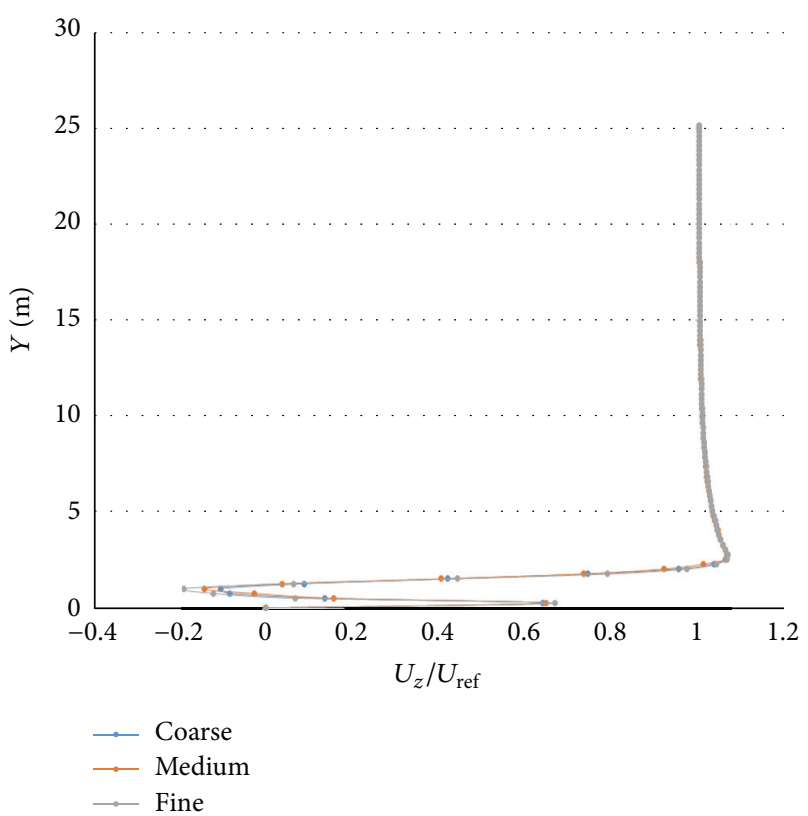

(a)

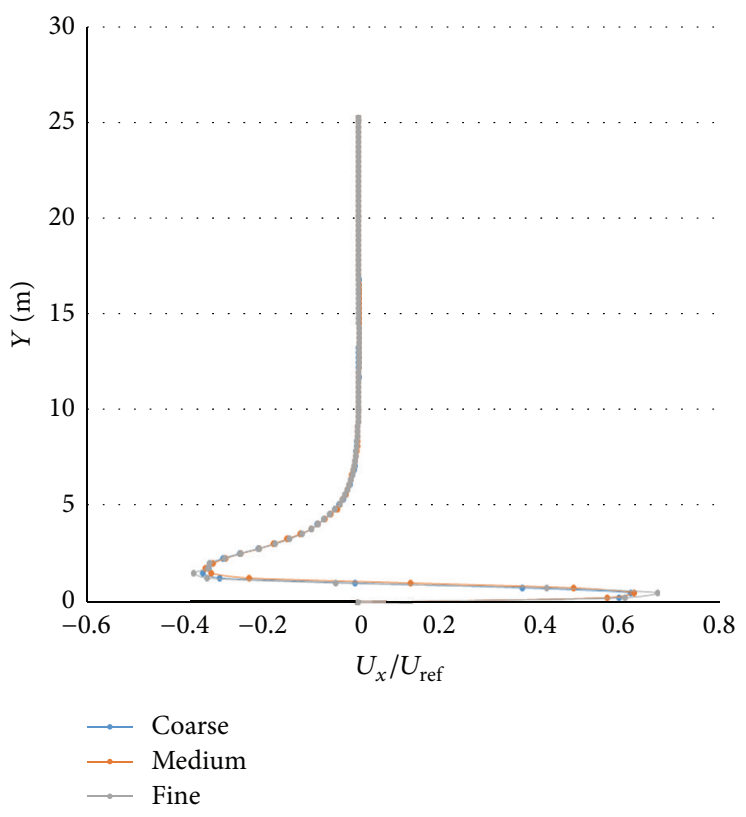

(b)

FIGURE 8: (a) Streamwise and (b) lateral wind velocity (m/s) profiles at location shown in Figure 7 using coarse, medium, and fine meshes.

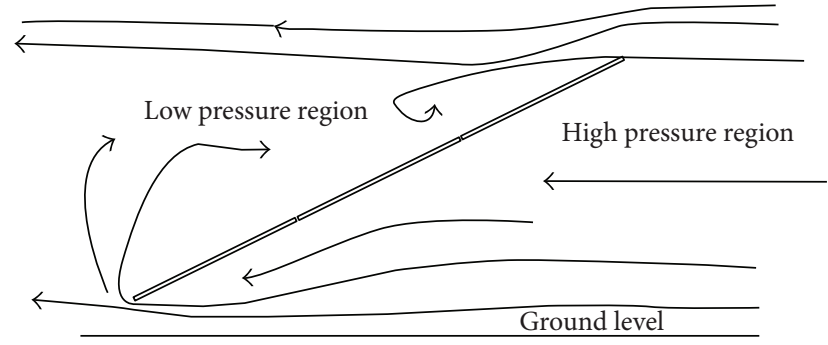

FIGURE 9: Schematic wind loading for inclined solar panel. The approach azimuthal angle is $0.0^{\circ}$ (north to south).

region. In Figure 17(b) the vortex has been replaced with two smaller strength vortices. This phenomenon resulted from flow mixture through holes and flow over and under passing panels tips. The holes existence reduced the velocity magnitude downwind of panels flow region and extended the low velocity flow region.

3.5. Wall Shear Stress. Wall shear stress $\left(\mathrm{N} / \mathrm{m}^{2}\right)$ contours at panels for up- and downwind sides are shown in Figures 18(a) and 18(b), respectively. For panels with holes, the wall shear stress contours at up- and downwind sides are shown in Figures 19(a) and 19(b), respectively. Maximum values reach $1.0 \mathrm{~N} / \mathrm{m}^{2}$ for either panel configuration. As it is expected and as it was previously mentioned, the holes drastically alter the flow field. Higher values appear on the upwind panel's side in either case. Panels with holes reduce the wall shear stress values. This particularly holds for the downwind side, Figure 19 (b). At $120.0^{\circ}$ approach angle and maximum upwind
TABle 4: Percentage wind load reduction. Negative sign indicates increase in load.

\begin{tabular}{lcccccc}
\hline Velocity/angle & $0.0^{\circ}$ & $30.0^{\circ}$ & $60.0^{\circ}$ & $120.0^{\circ}$ & $150.0^{\circ}$ & $180.0^{\circ}$ \\
\hline $6.0(\mathrm{~m} / \mathrm{s})$ & 5.16 & -0.32 & 2.86 & 12.53 & 6.28 & 0.96 \\
$8.0(\mathrm{~m} / \mathrm{s})$ & 6.46 & -0.32 & 2.88 & 12.39 & 5.40 & 0.66 \\
$10.0(\mathrm{~m} / \mathrm{s})$ & 5.18 & -0.41 & 2.80 & 11.83 & 4.60 & 2.80 \\
$12.0(\mathrm{~m} / \mathrm{s})$ & 5.86 & -0.48 & 2.86 & 11.22 & 4.60 & 0.80 \\
$14.0(\mathrm{~m} / \mathrm{s})$ & 6.18 & -0.44 & 2.79 & 12.43 & 4.60 & 1.72 \\
\hline
\end{tabular}

velocity the wall shear stress contours at up- and downwind side are shown in Figures 20(a) and 20(b), respectively. The flow field has now been completely altered with high wall shear stresses.

3.6. Loads. The load calculation is based on the area-average pressure differences between up- and downwind panel side surfaces. In percentage terms the wind loading does not follow the increased upwind velocity and subsequently the increased loading. The maximum wind loading, in descending approach azimuthal angles, order is $30.0^{\circ}, 0.0^{\circ}, 180.0^{\circ}$, $60.0^{\circ}, 120.0^{\circ}$, and $150.0^{\circ}$. The $0.0^{\circ}$ approach azimuthal angle case, under all upwind velocities, yields the highest load reduction. Percentage wind load reduction between conventional panels and panels with holes is shown in Table 4 . Percentage load reductions appear at all approach angles except at the $30.0 \%$. Even in this case the load increase is marginal. The loading reduction, in the arrayed set of panels with holes, ranges from $0.8 \%$ to $12.53 \%$. At $0.0^{\circ}$ approach angle, the loading reduction for the upwind velocities ranges between $5.16 \%$ and $6.46 \%$. Under all upwind velocities, the 


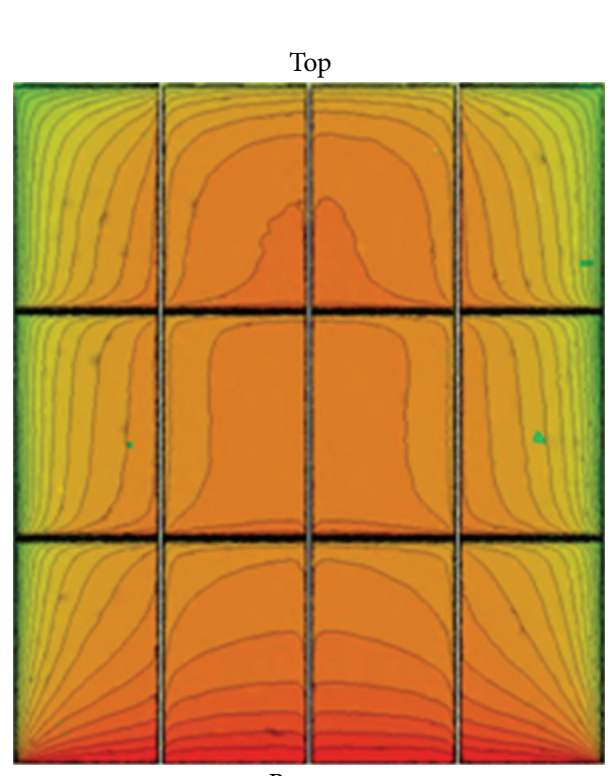

Bottom

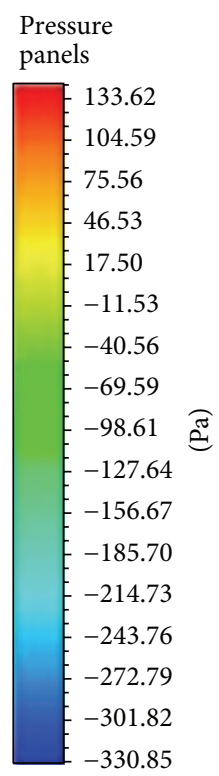

(a)

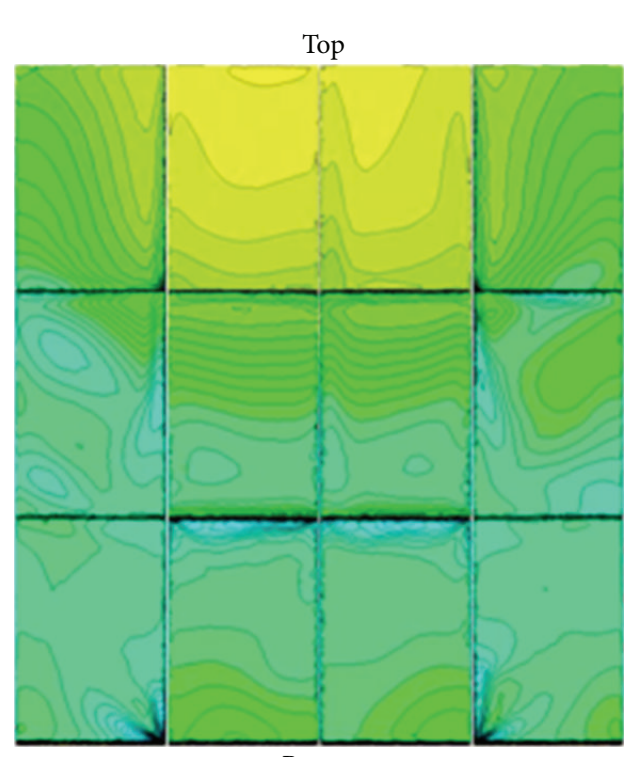

Pressure panels

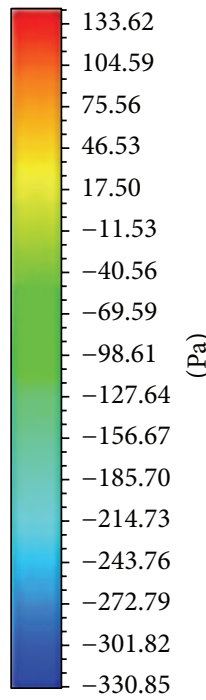

(b)

FIGURE 10: Static pressure $\left(\mathrm{N} / \mathrm{m}^{2}\right)$ contours at conventional panels: (a) upwind side and (b) downwind side.

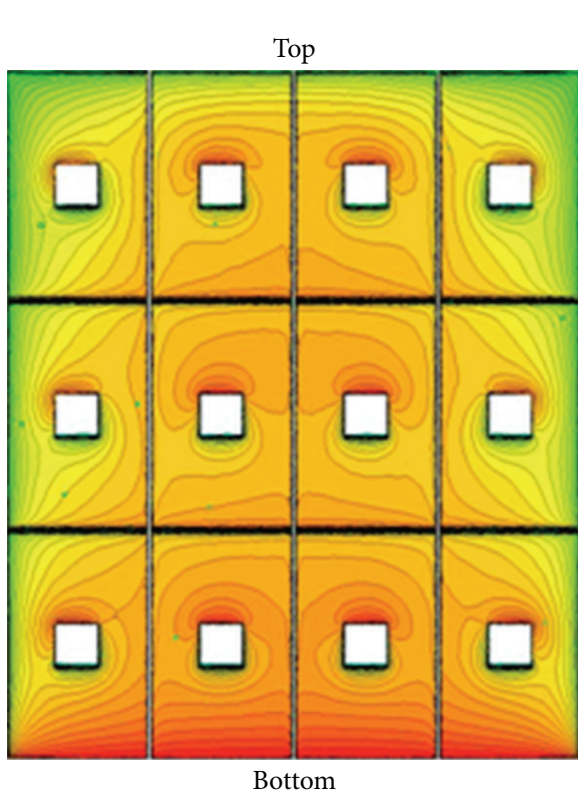

(a)
Pressure contour 1

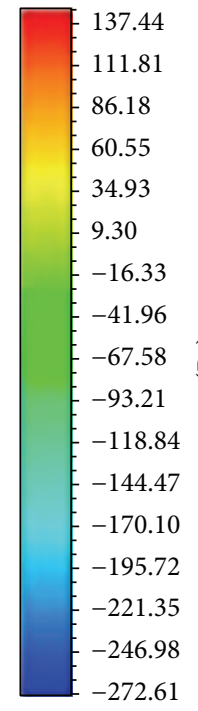

272.61
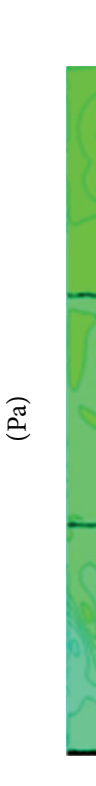

Top

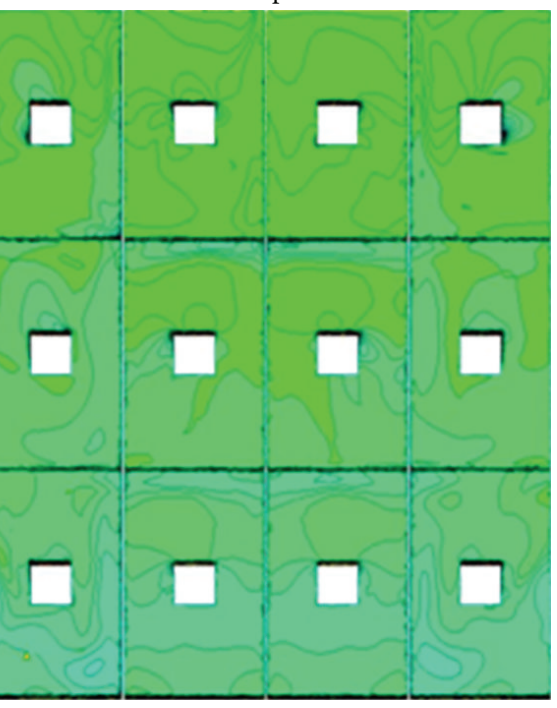

(b)
Pressure contour 1

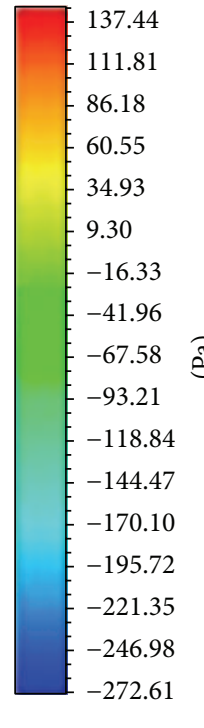

\section{๑ิ}

FIGURE 11: Static pressure $\left(\mathrm{N} / \mathrm{m}^{2}\right)$ contours at panels with holes: (a) upwind side and (b) downwind side.

percentage load reduction is higher at $120.0^{\circ}$. The maximum load reduction occurs at $6.0 \mathrm{~m} / \mathrm{s}$ upwind velocity and $120.0^{\circ}$ approach angle.

3.7. Velocity and Approach Azimuthal Angle. Velocity magnitude $(\mathrm{m} / \mathrm{s})$ contours at maximum upwind velocity for panels with holes and (a) $0.0^{\circ}$, (b) $30.0^{\circ}$, (c) $60.0^{\circ}$, (d) $120.0^{\circ}$, (e) $150.0^{\circ}$, and (f) $180.0^{\circ}$ approach angles (Section 2, Figure 12) are shown in Figure 21. The velocity flow field is drastically altered with the approach angle. At flow regions adjacent to upwind side, the velocity magnitude is relatively high in comparison to the adjacent downwind flow region. Maximum velocity magnitude is $\sim 19.0 \mathrm{~m} / \mathrm{s}$. Within holes the velocity magnitude increases due to flow area reduction. Symmetrical flow field develops at $0.0^{\circ}$ and $180.0^{\circ}$ approach azimuthal angles. The velocity attains its maximum value at panel corners which the flow at first encounters. This is true for all approach azimuthal angles. 


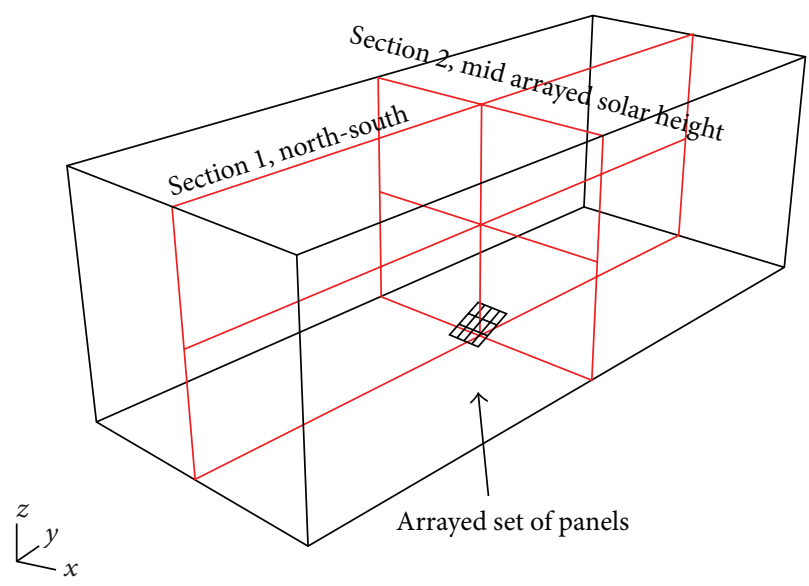

FIGURE 12: Schematic diagram showing two arrayed set solar panel cross sections used for results presentation.

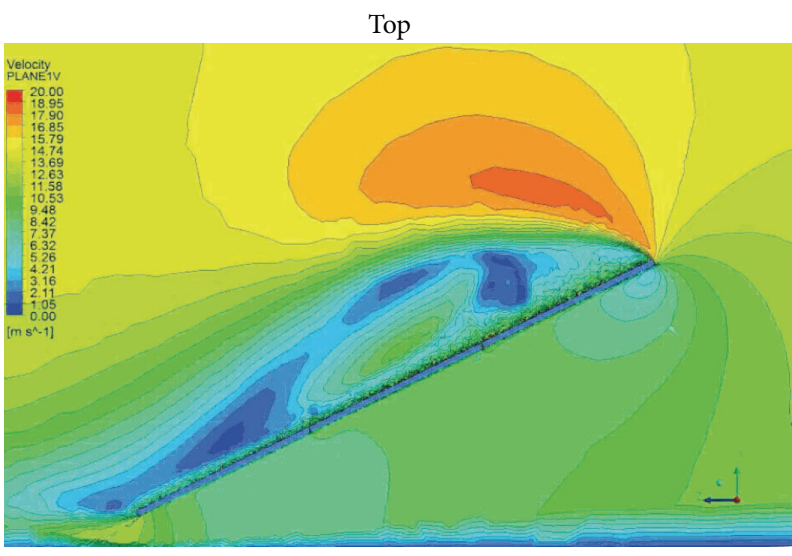

Bottom

(a)

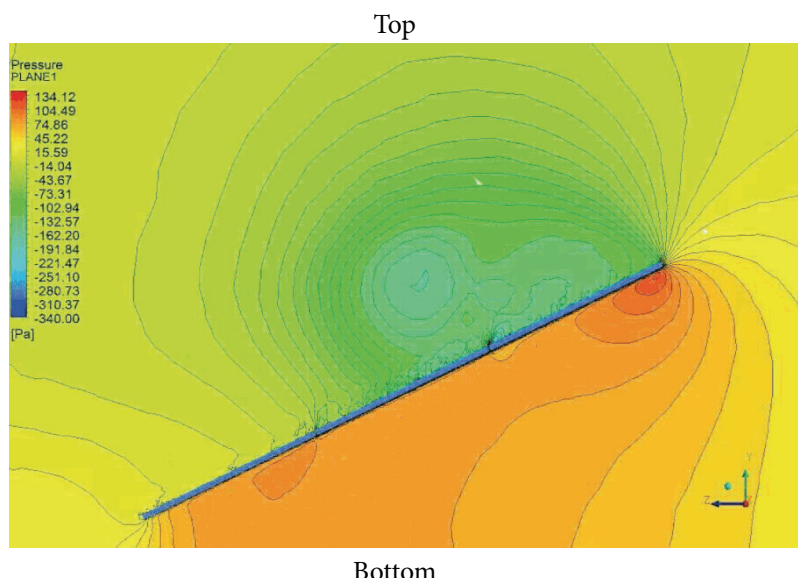

Bottom

(b)

FIGURE 13: (a) Velocity magnitude $(\mathrm{m} / \mathrm{s})$ and (b) static pressure $\left(\mathrm{N} / \mathrm{m}^{2}\right)$ contours at conventional panels, Section 1, Figure 12, wind from right to left.

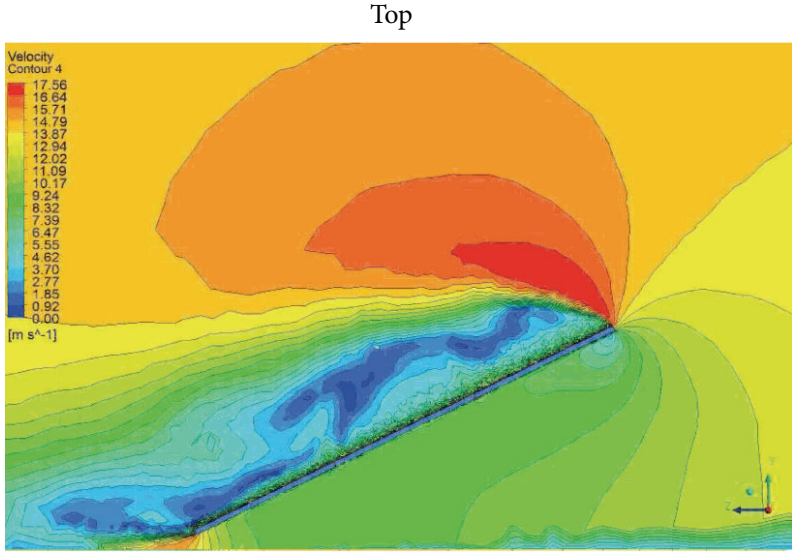

Bottom

(a)

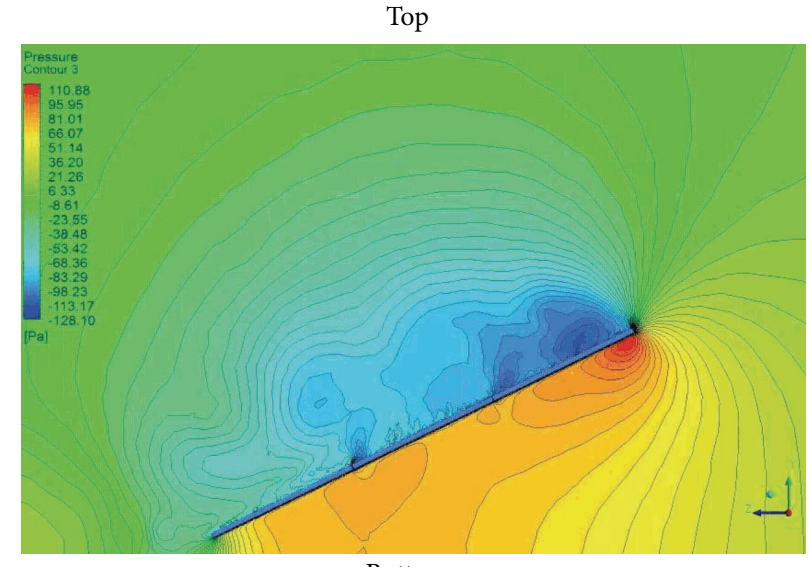

Bottom

(b)

FIGURE 14: (a) Velocity magnitude $(\mathrm{m} / \mathrm{s})$ and (b) static pressure $\left(\mathrm{N} / \mathrm{m}^{2}\right)$ contours at panels with holes, Section 1 , Figure 12 , wind from right to left. 


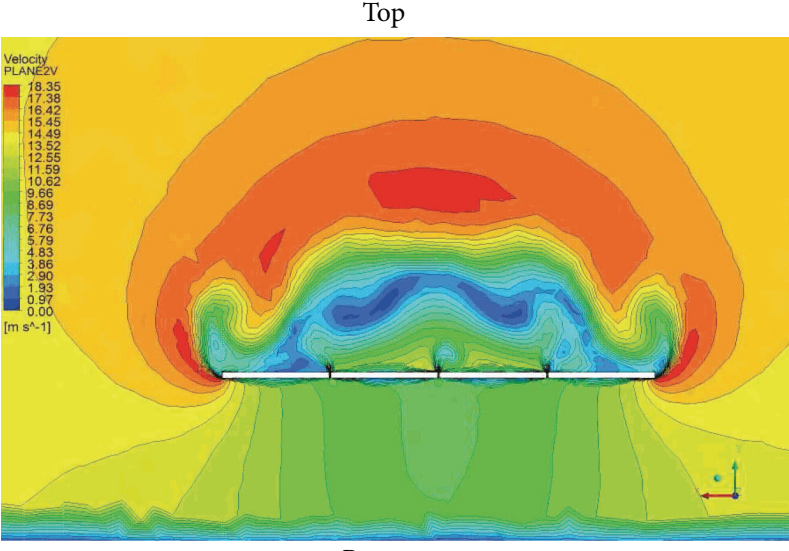

Bottom

(a)

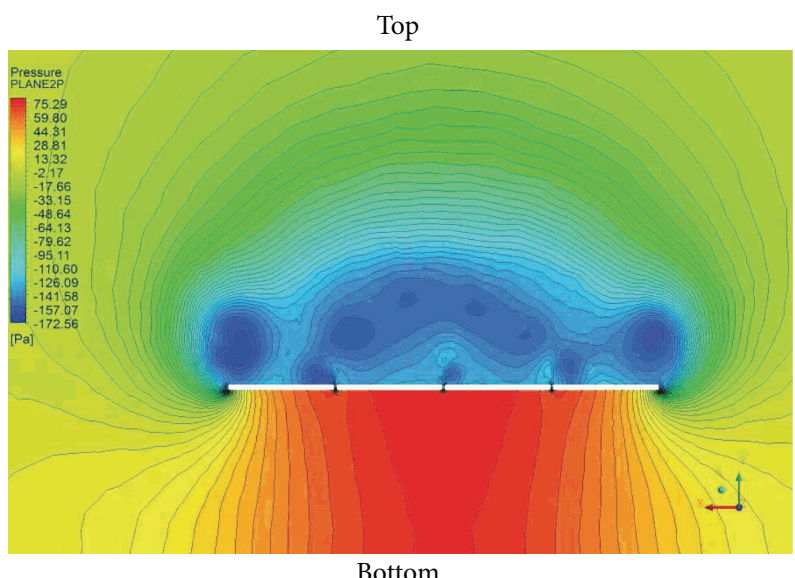

(b)

Figure 15: (a) Velocity magnitude $(\mathrm{m} / \mathrm{s})$ and (b) static pressure $\left(\mathrm{N} / \mathrm{m}^{2}\right)$ contours at conventional panels, Section 2, Figure 12 , wind from bottom to top.

Top

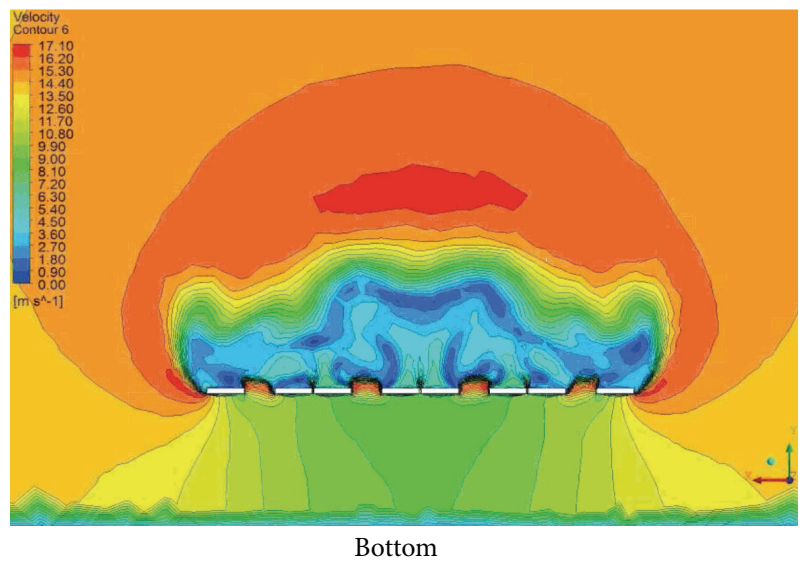

(a)

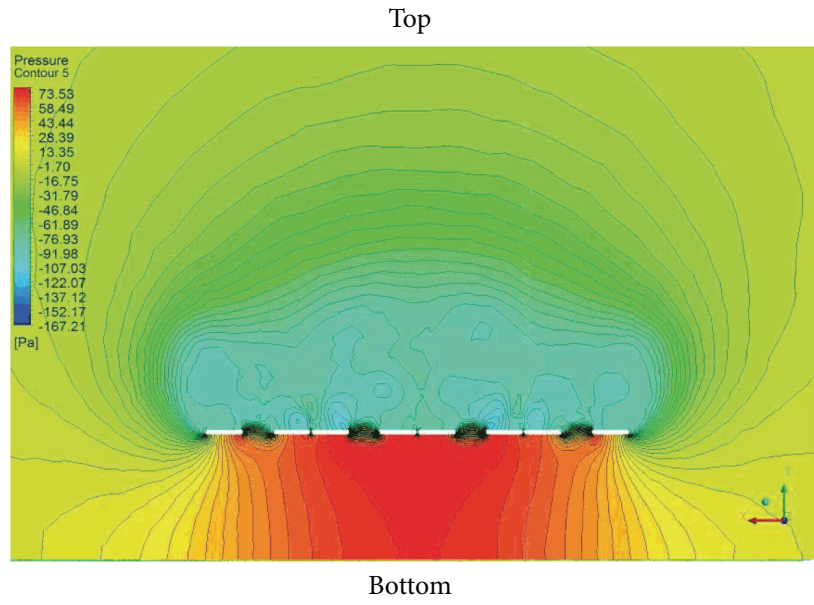

(b)

FiguRE 16: (a) Velocity magnitude $(\mathrm{m} / \mathrm{s})$ and (b) static pressure $\left(\mathrm{N} / \mathrm{m}^{2}\right)$ contours at panels with holes, Section 2, Figure 12, wind from bottom to top.

\section{Discussion}

The wind forces acting on panels can cause severe mechanical problems. Knowing the flow field around panels and its interaction with the structure is of paramount importance in minimizing the structural damaging effects. Panel loading depends on wind speed and its direction, height of the panel above the ground, and the relative inclination angle of the panel over the ground surface. An accurate determination of the wind loading is an important factor in deciding what degree of safety and economy can be achieved. Current analysis does not perform parametric analysis related either to panel height location above ground surface or to panel inclination effects. Furthermore, the ground roughness effects are not included in the analysis. Main purpose is to investigate the wind loading using panels with holes and to compare the load reduction from a conventional arrayed set of panels. Each panel type exposes to the wind the same panel surface area. Henceforth, the load reduction would be meaningful.

Higher wall shear stresses develop on the upwind side and mostly in regions close to the perimeter of the panel holes. Always wall shear stresses are considerably lower to static pressures (loads). Large values occur at maximum upwind velocity and $30.0^{\circ}$ approach angle. High upwind velocities and not approach angles are responsible for large wall shear stresses. The developed flow pattern is a highly complex one and this is more evident at the downwind sides of the panels (fitted or not with holes).

High positive wind forces, that is, forces acting in the direction up- to downwind panel surface, develop with panels fitted with holes at $0.0^{\circ}, 30.0^{\circ}$, and $60.0^{\circ}$ approach angles. However, for the $120.0^{\circ}, 150.0^{\circ}$, and $180.0^{\circ}$ approach angles the emerged forces are negative in the sense that they act in the 


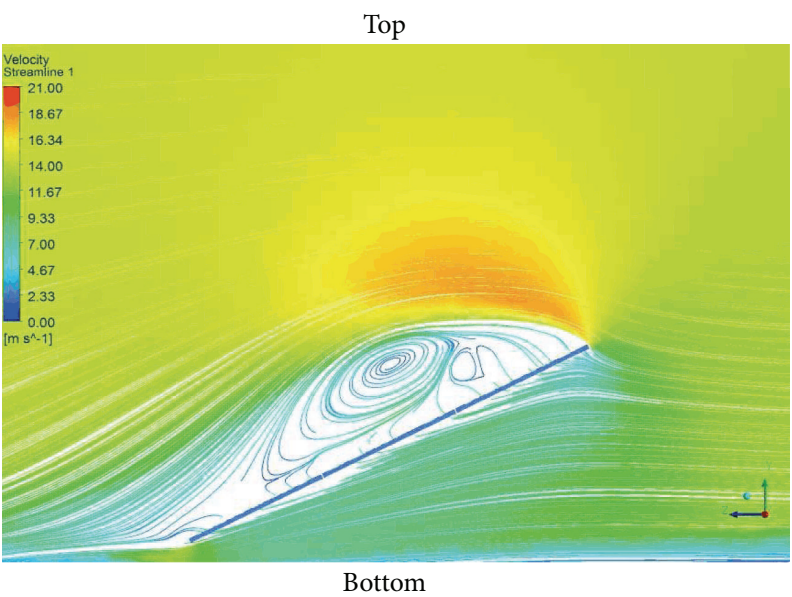

(a)

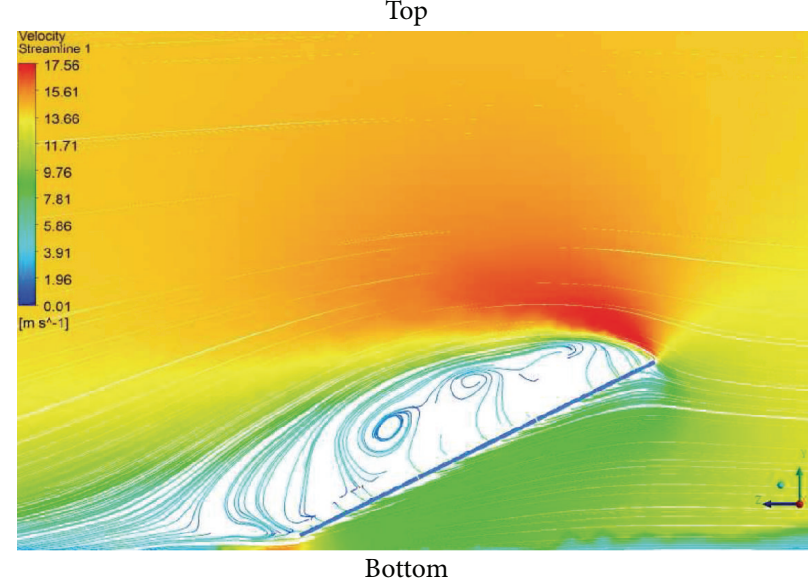

(b)

FIGURE 17: Streamlined velocity magnitude (m/s) contours at (a) conventional panels and (b) panels with holes, Section 1, Figure 12, wind from right to left.

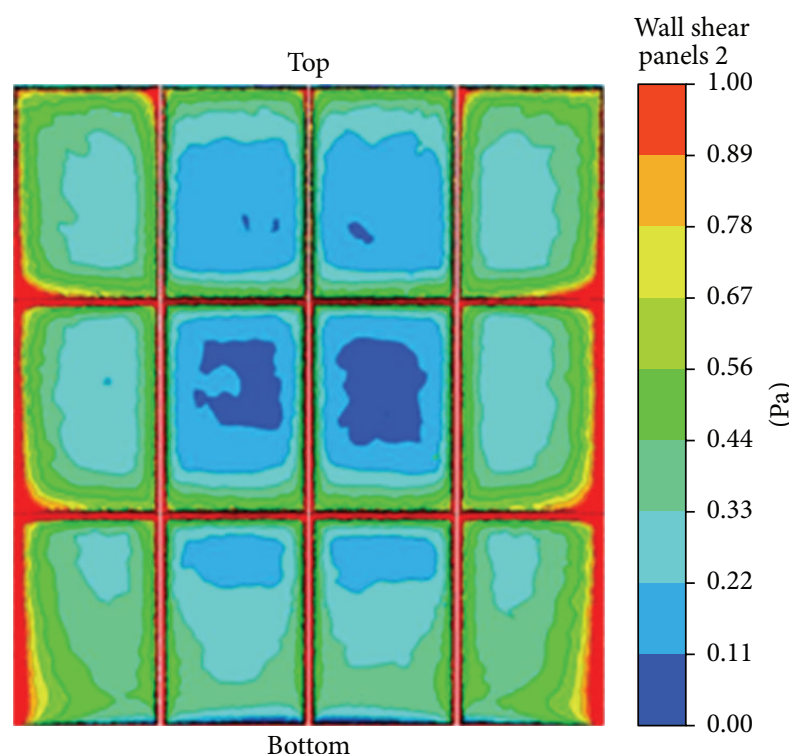

(a)

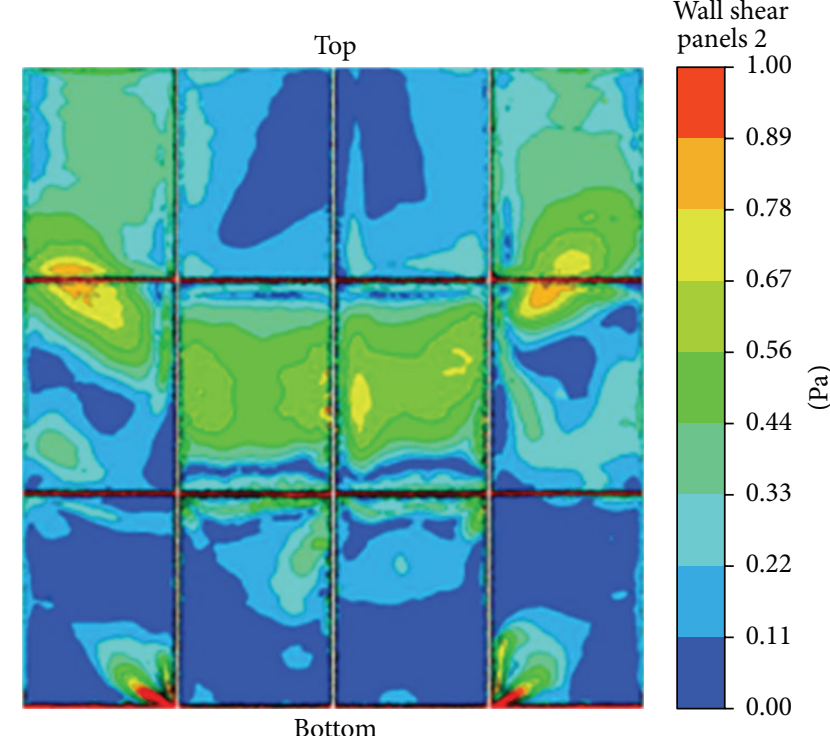

(b)

Figure 18: (a) Wall shear stress $\left(\mathrm{N} / \mathrm{m}^{2}\right.$ ) contours at conventional panels: (a) upwind side and (b) downwind side.

direction down- to upwind panel surface. Force differences acting on panels fitted with holes are less powerful since the wind finds effective escape corridors through the panel holes and gaps. The holes within each panel and the gap between panels allow high momentum (velocity) wind to flow through and reduce the windward pressure, as well as the negative pressure acting on the back panels side. In Tables 5 and 6, the acting forces are appearing in descending order for conventional panels and for those fitted with holes, respectively. Number 1 indicates the highest possible wind force while 30 denotes the lowest one. Bold font values in Tables 5 and 6 indicate that the wind force ranking has been changed. As it is expected, the forces are higher at the maximum upwind velocity. However, the maximum wind load reduction in percentage terms does not follow the increased upwind velocity. At $90.0^{\circ}$ approach angle the acting forces over the panel surface are minimal since the wind flows parallel to side panel walls (facing the panel width). The maximum upwind velocity at $30.0^{\circ}$ approach angle yields the highest possible force on the panels with either conventional or solar panels fitted with holes. The maximum wind loading in descending order for the approach angles is $30.0^{\circ}, 0.0^{\circ}$, $180.0^{\circ}, 60.0^{\circ}, 120.0^{\circ}$, and $150.0^{\circ}$.

The wind loading reduction using holes in the arrayed set of panels ranges from $0.8 \%$ to $12.53 \%$. The maximum load reduction occurs at $6.0 \mathrm{~m} / \mathrm{s}$ upwind velocity and $120.0^{\circ}$ approach angle. Under all tested upwind velocities, the percentage load reduction is higher at this angle. For the 


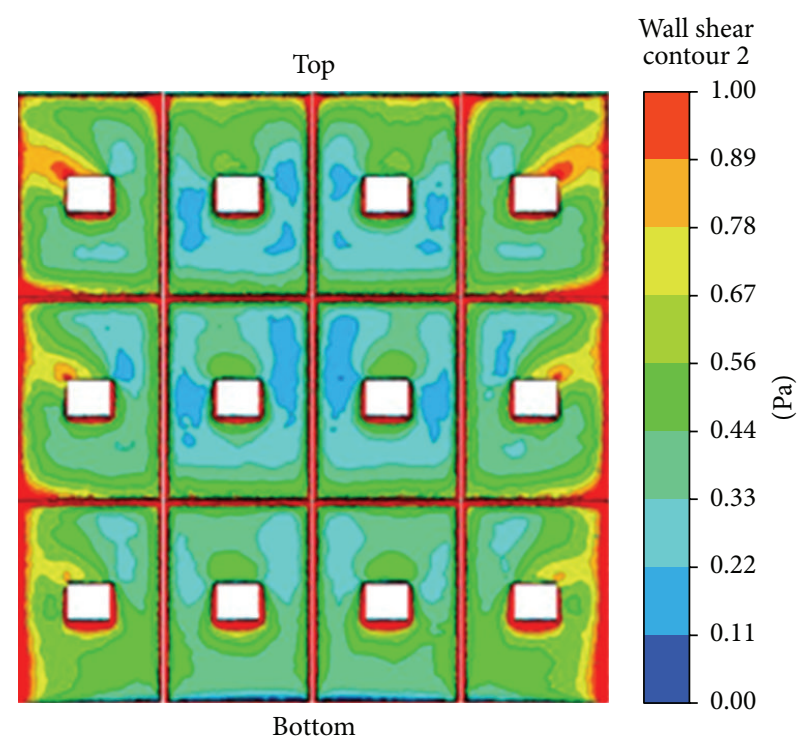

(a)

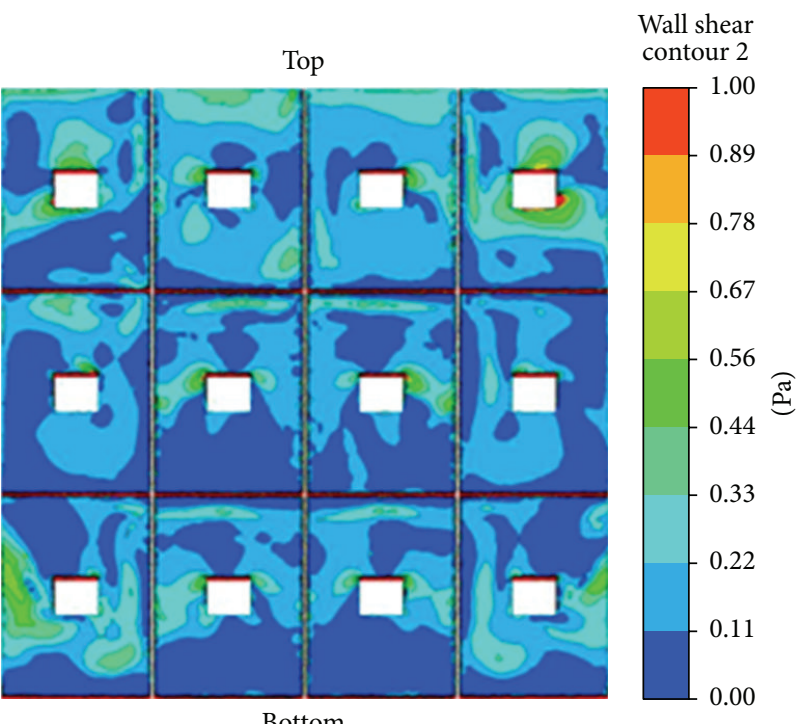

(b)

FIGURE 19: Wall shear stress $\left(\mathrm{N} / \mathrm{m}^{2}\right)$ contours at panels with holes: (a) upwind side and (b) downwind side.

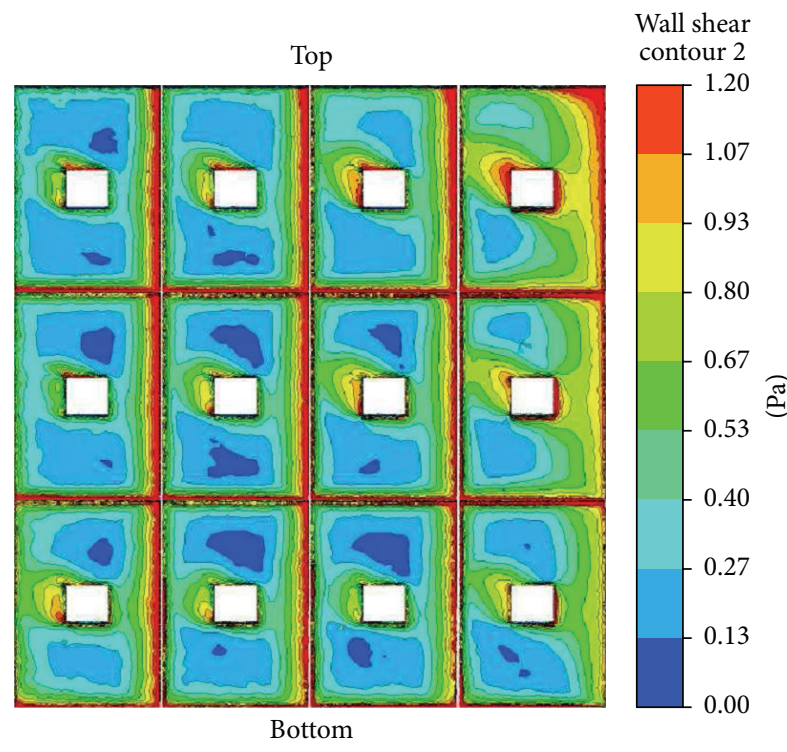

(a)

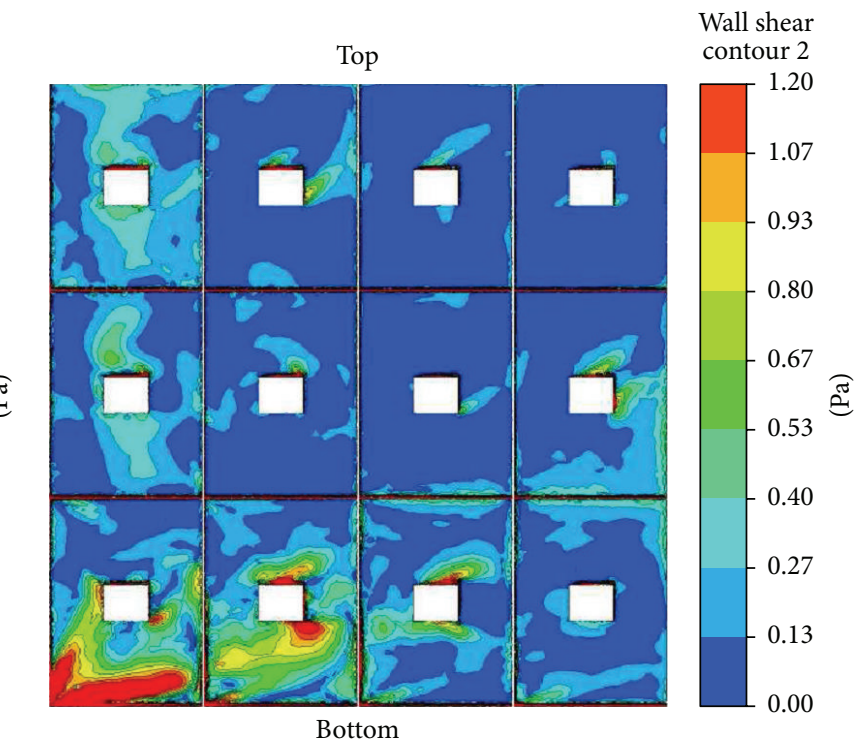

(b)

FIGURE 20: Wall shear stress $\left(\mathrm{N} / \mathrm{m}^{2}\right)$ contours at panels with holes with $120.0^{\circ}$ approach angle and maximum upwind velocity: (a) upwind side and (b) downwind side. Arrows show the wind direction (azimuthal angle).

$0.0^{\circ}$ approach angle the reduction in loading for all upwind velocities ranges between $5.16 \%$ and $6.46 \%$. At $30.0^{\circ}$ approach angle, under all upwind velocities, the percentage wind load increases.

Ogedengbe [13] conducted a series of pressure measurements (PIV technique) over panels on, similar to currently tested approach, azimuthal angles over panels inclined at $25.0^{\circ}$ and $40.0^{\circ}$ to the ground surface. They concluded that the gaps between each panel unit influenced the wind loading on the panel. Their research work findings closely approximate to the current numerically calculated research work results.
However, they used experimental techniques and they were interested in panel gaps effects and reducing the wind loading with other means rather than panels with holes. Chung et al. [3] found that the wind uplift was effectively reduced with a guide plate inserted normal to the wind direction. Shademan and Hangan [6] also observed that at a specific distance between two sets of panels the drag coefficient for the downstream sets of panels reaches a minimum. Furthermore, Shademan et al. [14] numerically analyzed the effects of lateral gap spacing between subpanels and the ground clearance at different wind speeds and directions. The bottom solar 


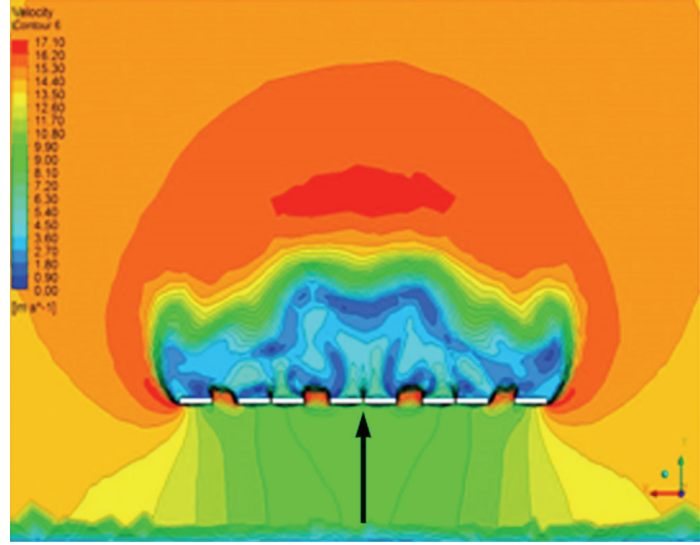

(a)

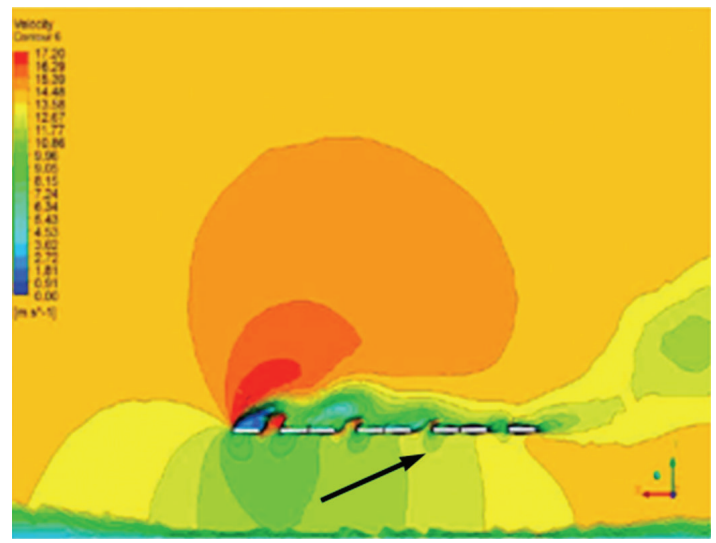

(c)

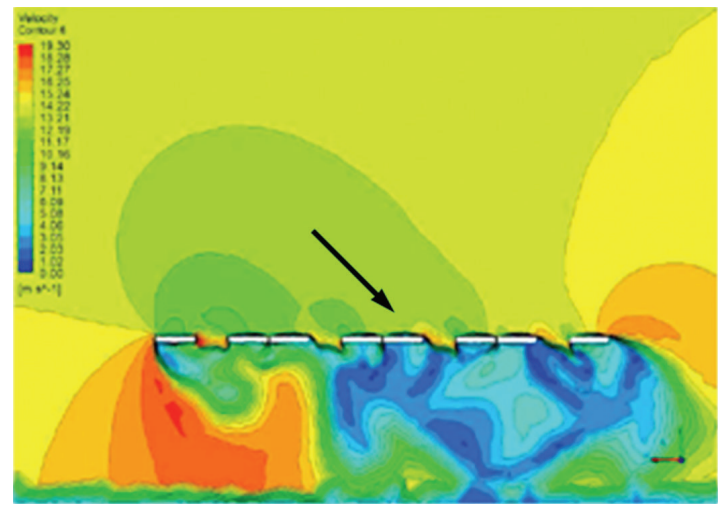

(e)

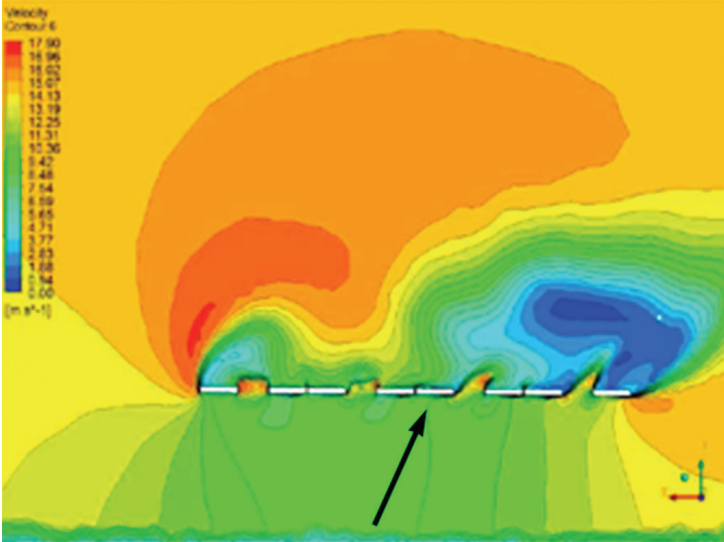

(b)

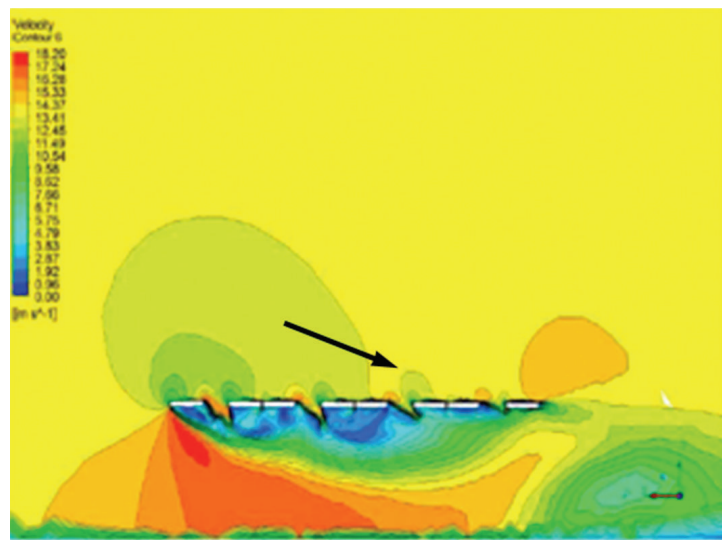

(d)

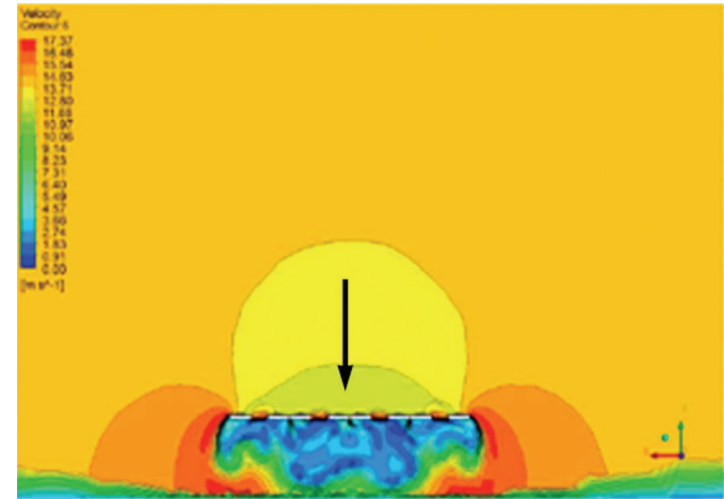

(f)

Figure 21: Velocity magnitude (m/s) contours at maximum upwind velocity $14.0 \mathrm{~m} / \mathrm{s}$. Panels with holes at (a) $0.0^{\circ}$, (b) $30.0^{\circ}$, (c) $60.0^{\circ}$, (d) $120.0^{\circ}$, (e) $150.0^{\circ}$, and (f) $180.0^{\circ}$ approach angles, Section 2, Figure 12; arrows show the wind direction (azimuthal angle).

subpanels experience higher wind load compared to the top subpanels, results similar to ours, Figures 10 and 11. Jubayer and Hangan [9] concluded that the maximum wind load occurs close to the leading edge for all four different wind directions $\left(0^{\circ}, 45^{\circ}, 135^{\circ}\right.$, and $\left.180^{\circ}\right)$, a conclusion that can be also made by our analysis, Figures 14(a) and 14(b). Moreover for $0^{\circ}$ and $180^{\circ}$ wind directions, symmetry was observed in both mean $C_{p}$ distributions and the wake structures, about the streamwise midline of the panel. Figures 10 and 11 of our analysis agree with this observation. Wind loads on solar panels were systematically investigated in wind tunnel, Peterka et al. [15]. They provided useful information, thus enriching the general literature, for the design of the solar panels mounted on buildings. Wind-induced loads on PV solar panels installed on roof tops were of main concern for Liu and Dragomirescu [16]. Measurements were conducted for a solar panel installed on a building. The maximum wind load of $1208.0 \mathrm{~N}$ was obtained on the northwest corner of 
TABLE 5: Wind load ranking magnitude for conventional panels. Number 1 indicates the highest possible wind force and number 30 the smallest one. Bold font values indicate that the wind force ranking has been affected in comparison to panels with holes.

\begin{tabular}{lccccc}
\hline $\begin{array}{l}\text { Angle/ } \\
\text { velocity }\end{array}$ & $\begin{array}{c}6.0 \\
(\mathrm{~m} / \mathrm{s})\end{array}$ & $\begin{array}{c}8.0 \\
(\mathrm{~m} / \mathrm{s})\end{array}$ & $\begin{array}{c}10.0 \\
(\mathrm{~m} / \mathrm{s})\end{array}$ & $\begin{array}{c}12.0 \\
(\mathrm{~m} / \mathrm{s})\end{array}$ & $\begin{array}{c}14.0 \\
(\mathrm{~m} / \mathrm{s})\end{array}$ \\
\hline $0.0^{\circ}$ & 24 & $\mathbf{1 7}$ & $\mathbf{9}$ & 5 & 2 \\
$30.0^{\circ}$ & 23 & $\mathbf{1 6}$ & 8 & $\mathbf{4}$ & 1 \\
$60.0^{\circ}$ & 28 & $\mathbf{2 1}$ & 14 & $\mathbf{1 0}$ & 6 \\
$120.0^{\circ}$ & 29 & $\mathbf{2 5}$ & $\mathbf{2 0}$ & $\mathbf{1 5}$ & 11 \\
$150.0^{\circ}$ & 30 & 27 & 22 & 18 & 12 \\
$180.0^{\circ}$ & $\mathbf{2 6}$ & 19 & 13 & 7 & $\mathbf{3}$ \\
\hline
\end{tabular}

TABLE 6: Wind load ranking magnitude for panels with holes. Number 1 indicates the highest possible wind force and number 30 the smallest one. Bold font values indicate that the wind force ranking has been affected in comparison to panels with holes.

\begin{tabular}{lccccc}
\hline $\begin{array}{l}\text { Angle/ } \\
\text { velocity }\end{array}$ & $\begin{array}{c}6.0 \\
(\mathrm{~m} / \mathrm{s})\end{array}$ & $\begin{array}{c}8.0 \\
(\mathrm{~m} / \mathrm{s})\end{array}$ & $\begin{array}{c}10.0 \\
(\mathrm{~m} / \mathrm{s})\end{array}$ & $\begin{array}{c}12.0 \\
(\mathrm{~m} / \mathrm{s})\end{array}$ & $\begin{array}{c}14.0 \\
(\mathrm{~m} / \mathrm{s})\end{array}$ \\
\hline $0.0^{\circ}$ & 24 & $\mathbf{1 6}$ & $\mathbf{1 0}$ & 5 & 2 \\
$30.0^{\circ}$ & 23 & $\mathbf{1 5}$ & 8 & $\mathbf{3}$ & 1 \\
$60.0^{\circ}$ & 28 & $\mathbf{2 0}$ & 14 & $\mathbf{9}$ & 6 \\
$120.0^{\circ}$ & 29 & $\mathbf{2 6}$ & $\mathbf{2 1}$ & $\mathbf{1 7}$ & 11 \\
$150.0^{\circ}$ & 30 & 27 & 22 & 18 & 12 \\
$180.0^{\circ}$ & $\mathbf{2 5}$ & 19 & 13 & 7 & $\mathbf{4}$ \\
\hline
\end{tabular}

the PV solar panel arrays. The field measurements indicated that the highest wind-induced stress is on the lower edge of the PV panel. Upwind panel sides exhibit higher stresses than downwind sides. Furthermore, lower upwind panel side also exhibits higher stress than the center or upper panel side. In addition to the field measurements Liu and Dragomirescu [16] performed analysis with the Large Eddy Simulation technique. Our computational results are close to measured and calculated results of theirs. Sensors located on edge of the downwind side exhibit stresses lower than the center line. This is also an interesting finding and it is verified by our analysis, Figure 15(b). The crosswind effects on the aerodynamic characteristics of residential inclined flat plate mounted with a horizontal cylinder are experimentally investigated, Wood et al. [17]. They conducted low wind tunnel velocity with $0.0^{\circ}$ to $135.0^{\circ}$ wind direction. High suction and fluctuating pressure were observed near the upwind corner of the structure. These findings are also observed in our research for the tested solar panels (conventional and fitted with holes). Current research work findings suggest that the gaps and the panel holes greatly affect the flow pattern and subsequently the wind load reduction under upwind velocities and approach angles. To the best of our knowledge there was not similar research work undertaken and subsequently published on panel wind loading reduction using holes.

\section{Conclusion}

Current research work findings suggest that the panel holes greatly affect the flow pattern and subsequently the wind load reduction. These panels reduced the velocity magnitude downwind of panels flow region and extended the low velocity flow region. Wind forces acting on panels fitted with holes are less powerful since the wind finds effective escape corridors through the panels. The maximum wind load reduction in percentage terms does not follow the increased upwind velocity. The maximum wind loading in descending order for the approach angles is $30.0^{\circ}, 0.0^{\circ}, 180.0^{\circ}$, $60.0^{\circ}, 120.0^{\circ}$, and $150.0^{\circ}$. The loading reduction in the arrayed set of panels ranges from $0.8 \%$ to $12.53 \%$. The maximum load reduction occurs at $6.0 \mathrm{~m} / \mathrm{s}$ upwind velocity and $120.0^{\circ}$ approach angle. Under all upwind velocities, the percentage load reduction is higher at $120.0^{\circ}$. The only case where there is a small increase of wind loading refers to $30.0^{\circ}$ approach angle. For the $0.0^{\circ}$ approach angle, the reduction in wind loading for the upwind velocities ranges between $5.16 \%$ and $6.46 \%$. Both the wind velocity and the angle of approach affect the wind loading on panels with or without holes. The current computational analysis indicates that it is possible to reduce wind loading considerably using panels with holes.

\section{Competing Interests}

The authors declare that they have no competing interests.

\section{References}

[1] L. Chevalien and J. Norton, Wind Loads on Solar Collector Panels and Support Structure, Aerospace Engineering Department, Texas A\&M University, College Station, Tex, USA, 1979.

[2] G. A. Kopp, D. Surry, and K. Chen, "Wind loads on a solar array," Wind and Structures, vol. 5, no. 5, pp. 393-406, 2002.

[3] K. Chung, K. Chang, and Y. Liu, "Reduction of wind uplift of a solar collector model," Journal of Wind Engineering and Industrial Aerodynamics, vol. 96, no. 8-9, pp. 1294-1306, 2008.

[4] C.-C. Chou, K.-M. Chung, and K.-C. Chang, "Wind loads of solar water heaters: wind incidence effect," Journal of Aerodynamics, vol. 2014, Article ID 835091, 10 pages, 2014.

[5] M. Shademan and H. Hangan, "Wind loading on solar panels at different inclination angles," in Proceedings of the 11th Americas Conference on Wind Engineering, San Juan, Puerto Rico, June 2009.

[6] M. Shademan and H. Hangan, "Wind loading on panels at different azimuthal and inclination angles," in Proceedings of the 5th International Symposium on Computational Wind Engineering (CWE '10), Chapel Hill, NC, USA, May 2010.

[7] G. Bitsuamlak, A. Dagnew, and J. Erwin, "Evaluation of wind loads on panel modules using CFD," in Proceedings of the 5th International Symposium on Computational Wind Engineering, Chapel Hill, NC, USA, 2010.

[8] R. Meroney and D. Neff, "Wind effects on roof-mounted solar photovoltaic arrays: CFD and wind-tunnel evaluation," in Proceedings of the The 5th International Symposium on Computational Wind Engineering, Chapel Hill, NC, USA, 2010. 
[9] C. M. Jubayer and H. Hangan, "Numerical simulation of wind effects on a stand-alone ground mounted photovoltaic (PV) system," Journal of Wind Engineering and Industrial Aerodynamics, vol. 134, pp. 56-64, 2015.

[10] P. Stangroom, CFD Modelling of Wind Flow, University of Nottingham, Nottingham, UK, 2004.

[11] B. Blocken, T. Defraeye, D. Derome, and J. Carmeliet, "Highresolution CFD simulations for forced convective heat transfer coefficients at the facade of a low-rise building," Building and Environment, vol. 44, no. 12, pp. 2396-2412, 2009.

[12] S. V. Patankar, Numerical Heat Transfer and Fluid Flow, Taylor \& Francis, Abingdon, UK, 1980.

[13] A. A. Ogedengbe, Experimental Investigation of Wind Effect on Solar Panels, The University of Western Ontario, London, Canada, 2013.

[14] M. Shademan, R. M. Barron, R. Balachandar, and H. Hangan, "Numerical simulation of wind loading on ground-mounted solar panels at different flow configurations," Canadian Journal of Civil Engineering, vol. 41, no. 8, pp. 728-738, 2014.

[15] J. A. Peterka, B. Bienkiewicz, N. Hosoya, and J. E. Cermak, "Heliostat mean wind load reduction," Energy, vol. 12, no. 3-4, pp. 261-267, 1987.

[16] Y. Liu and E. Dragomirescu, "Field measurements and CFD simulation for wind effect on PV solar panels mounted on flat roofs," in Proceedings of the World Congress on Advances in Civil Engineering and Materials Research (ACEM '14), Busan, South Korea, 2014.

[17] G. S. Wood, R. O. Denoon, and K. C. S. Kwok, "Wind loads on industrial solar panel arrays and supporting roof structure," Wind \& Structures, vol. 4, no. 6, pp. 481-494, 2001. 


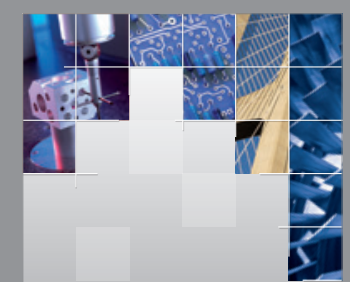

\section{Enfincering}
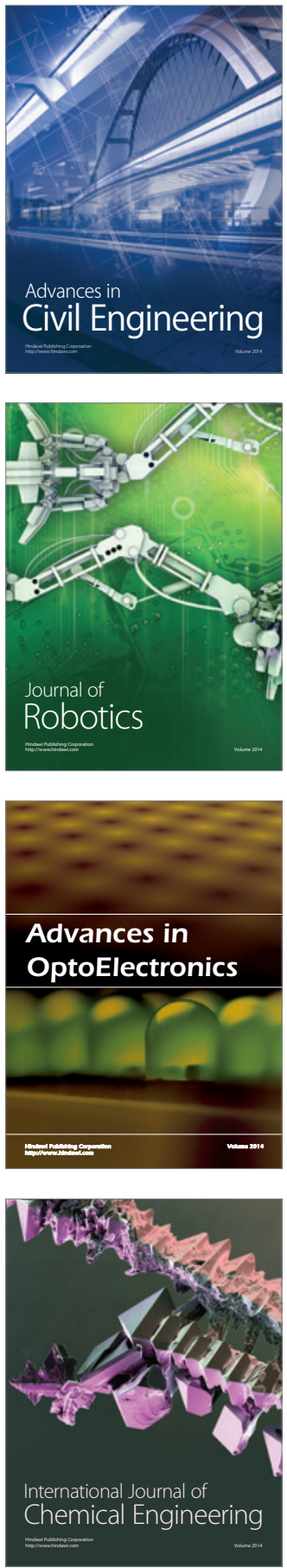

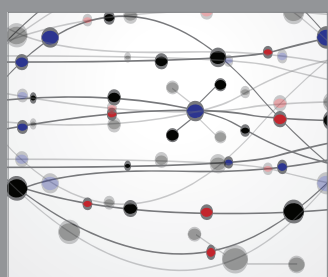

The Scientific World Journal

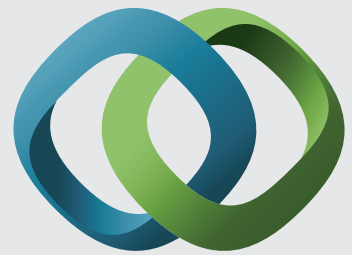

\section{Hindawi}

Submit your manuscripts at

http://www.hindawi.com
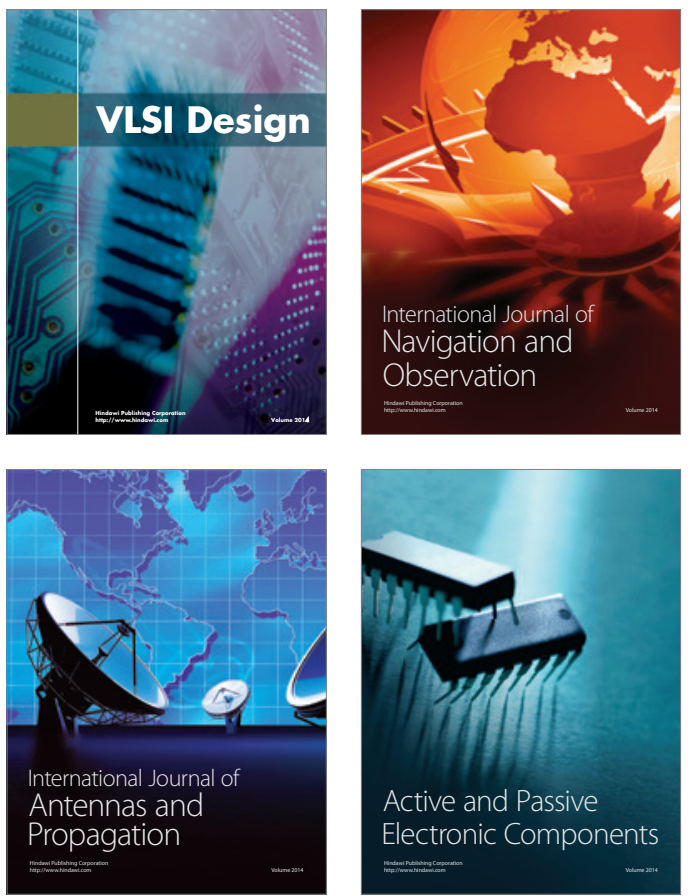
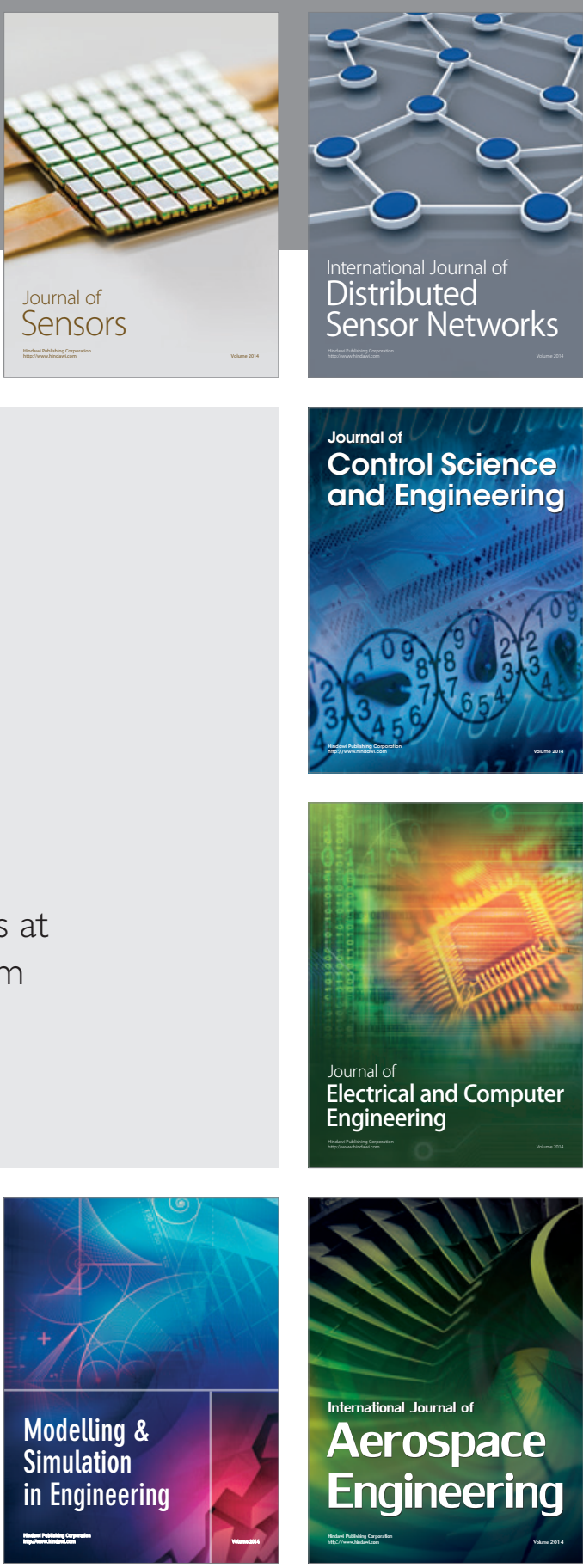

International Journal of

Distributed

Sensor Networks

Journal of

Control Science

and Engineering
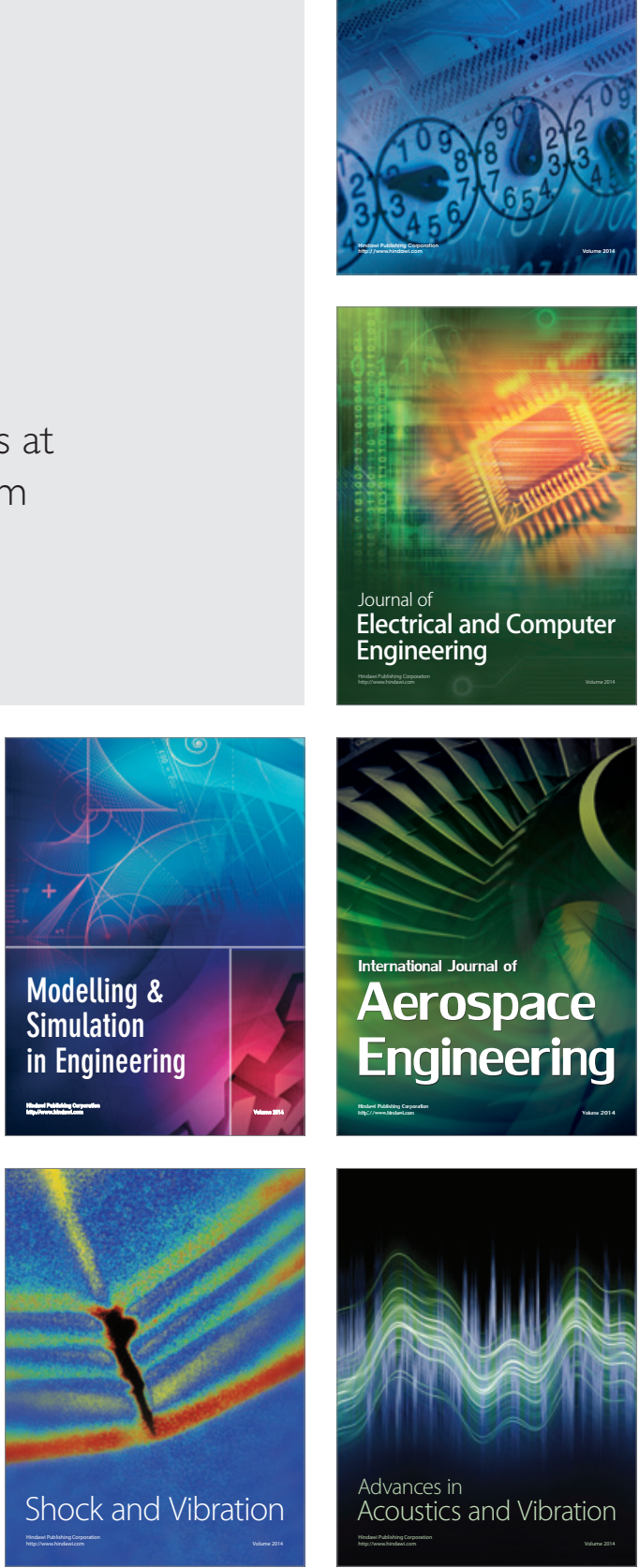